\title{
Chapter 8 Ionic liquids and deep eutetic solvents in the field of environmental monitoring
}

\author{
Inês S. Cardoso, Augusto Q. Pedro, Armando J. D. Silvestre and \\ Mara G. Freire*
}

CICECO - Aveiro Institute of Materials, Chemistry Department, University of Aveiro, 3810-193 Aveiro, Portugal

*Corresponding Author

E-mail address: maragfreire@ua.pt; Tel: +351-234401422; Fax: +351-234370084 


\section{Abstract}

A growing number of compounds resulting from human activities are continuously released into the environment. The majority of these compounds possess serious environmental threats, reinforcing the need of environmental monitoring both to understand their impact on the environment and on human health, and to create strategies to revert these risks. Although with serious impact, these pollutants are usually present in trace levels in environmental samples, turning their identification and accurate quantification a major challenge. To overcome this drawback, pretreatment techniques are usually employed, both to eliminate interferences and to enrich the sample in the target pollutants. Within the significant developments achieved in this field, ionic liquids (ILs) and deep eutectic solvents (DES) have shown to lead to relevant improvements in the enrichment factor and target pollutants recovery and in the limit of detection of the analytical technique when used as alternative solvents in pretreatment techniques of environmental matrices. These have been applied in the pretreatment of wastewaters, industrial effluents, human fluids, wine, milk, honey, fish, macroalgae, vegetables and soil. A wide number of pollutants, such as polyaromatic hydrocarbons (PAHs), active pharmaceutical ingredients (APIs), endocrine disruptors, pesticides, UV filters and heavy metals are some of the most commonly analyzed target pollutants. In this work we review and discuss the use of ILs and DES as 
alternative solvents in pretreatment strategies in the field of environmental monitoring. We also highlight the most recent works on this area and provide new insights and directions to follow in this field.

\section{Keywords}

Environmental monitoring, trace-level pollutants, environmental matrices, green analytical chemistry, pretreatment, ionic liquid, deep eutectic solvent 


\section{Introduction}

As the world's population continues to grow and as technology continues to develop, a growing number of compounds possessing serious environmental threats resulting from human activities are released into the environment [1]. Given the negative impact on living beings (and ultimately on humans) resulting from the exposure to these substances, it is crucial to evaluate their persistent, bio-accumulating and toxic character $[2,3]$. These substances, which comprise pharmaceuticals, pesticides, endocrine disruptors, heavy metals and several other compounds, and although appearing at trace-levels, can severely affect growth, reproduction and development of organisms. They can also compromise the immune system, leading to behavioral changes, cancer, diabetes, thyroid problems, among others $[2,4,5]$. The major exposure route of living beings to these contaminants is by ingestion, which leads to bioaccumulation and biomagnification, particularly towards species at the top level of the food chain [4], as schematized in Figure 10.1.

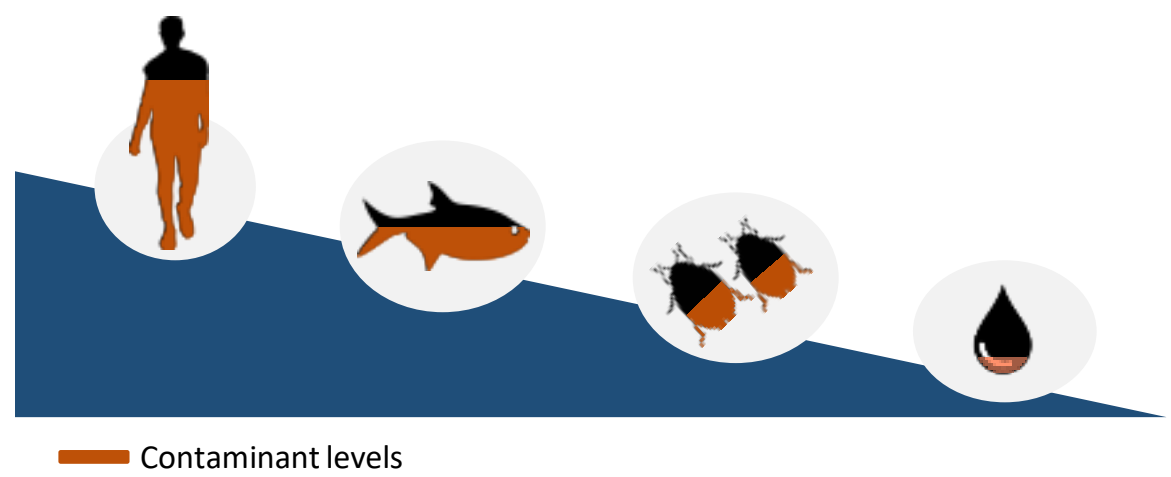

Fig. 10.1. Representation of the biomagnification process. 
A relevant factor contributing to the contamination of soils and water is the global growth of agricultural production, which has been accomplished through the intensive use of pesticides and chemical fertilizers. These compounds can either infiltrate into the soil or directly enter into aquatic systems, causing significant contamination of terrestrial ecosystems [6]. The presence of heavy metals is due to agricultural activities or to their release in pharmaceutical, industrial and domestic effluents [7]. An additional significant source of contamination derives from the extensive use of pharmaceuticals, both by humans and in animals. Many drugs are only partially retained, treated or removed in wastewater treatment plants, therefore being present in relevant levels in the aquatic environment [8]. Based on the exposed, there has been an increasing environmental awareness and interest in creating improved monitoring techniques to all sorts of pollutants, foreseeing to reduce the environmental impact of human activities and ultimately the impact over humans themselves. This trend can be further confirmed by the increasing number of reports dealing with pollutants monitoring programs according to a literature survey conducted from 2000 to 2018, as shown in Figure 10.2 [9]. 


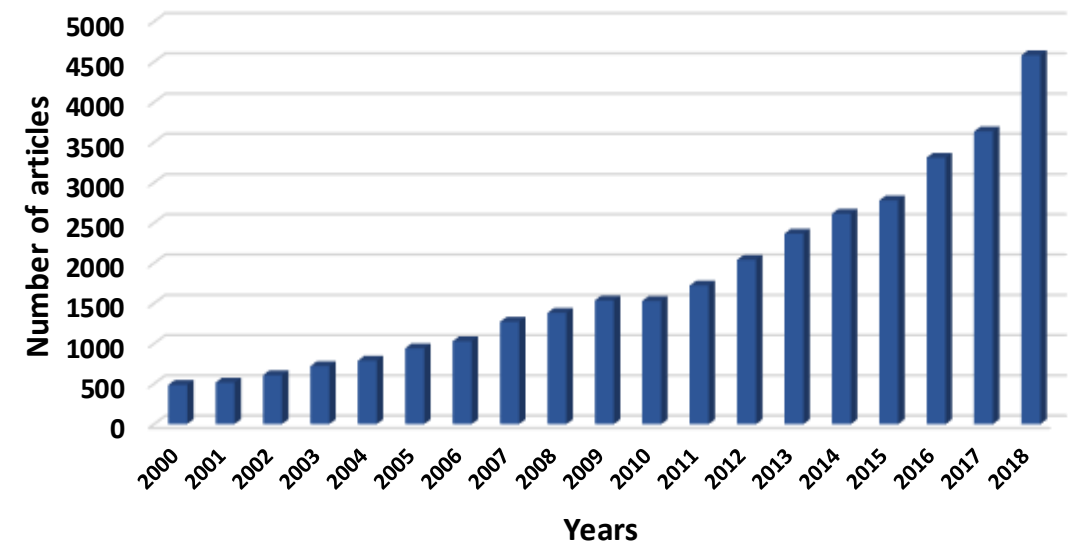

Fig. 10.2. Number or articles per year (from 2000 to $25^{\text {th }}$ November 2018) dealing with the monitoring of contaminants of environmental concerns. The search was carried out in the ScienceDirect database using as keywords "water", "environment", "monitoring", "contaminant" and "pollutant".

The increasing awareness of these aspects and also the scientific interest they trigger reinforce the need of establishing new environmental regulations and goals [9], both to preserve environment and human safety. There is thus an expanding need for simple, rapid, and costeffective screening methods to ensure that target pollutants are kept within acceptable levels. Environmental research is entering in a stage where analytical sciences play a vital role, allowing detailed environmental studies and confirming whether environmental goals have been met $[9,10]$. Nonetheless, it is important to highlight the fact that neither analytics nor monitoring can solve any problems regarding pollution or environment degradation. They merely represent compelling tools that can provide relevant information required for a supported evaluation of the environment contamination level, ultimately 
relevant for decision making [3]. The application areas related to environmental monitoring are summarized in Figure 10.3.

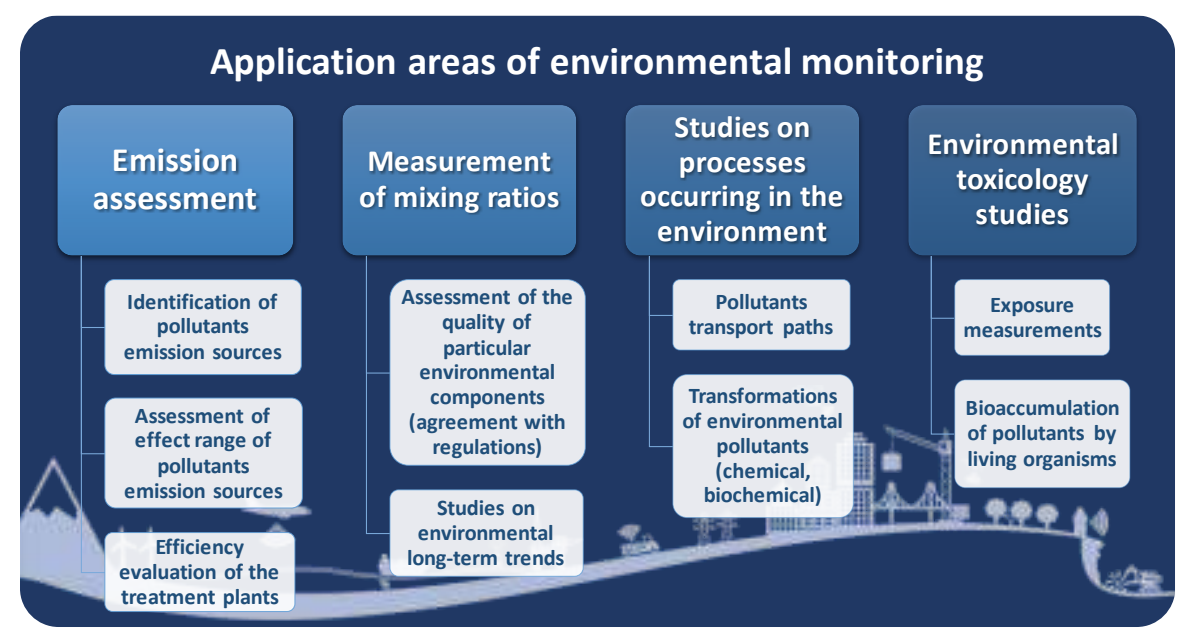

Fig. 10.3. Application areas of environmental monitoring (adapted from [3]).

Significant technological progresses have been accomplished to identify and quantify several hazardous chemicals, including herbicides [11-14], pesticides [15-20], insecticides [21], polycyclic aromatic hydrocarbons (PAHs) [22-25], heavy metals [26-29], endocrine disruptors [29-31], active pharmaceutic ingredients (APIs) [32-37] and other organic pollutants [38-41]. Most of these substances display toxicity and disruptive effects, even at trace levels. However, in samples whose matrices are complex, the presence of interferents plays a significant role [2]. There are therefore several sample preparation techniques intended to reduce potential interferences from the sample matrix, while concentrating the target analytes for a more accurate 
identification and quantification in environmental samples. Examples of sample preparation techniques or pretreatment methods include organic digestion/dissolution, solid-phase extraction, liquid-phase extraction, aqueous biphasic systems and a wide range of microextraction procedures, which will be further reviewed and discussed. Overall, it is highly desirable to develop reproducible pretreatment methods that can be applied independently of the sample matrix and target pollutant and interferences [4].

Along with the environmental awareness, Green Chemistry actively seeks for new processes and chemical products aiming at reducing or eliminating the use of hazardous substances and waste [42]. One of the main goals in the Green Chemistry Analytical field consists on the application of sustainable solvents to replace the commonly applied volatile organic compounds, either in the extraction, pretreatment or quantification steps [43]. In this context, solvents such as ionic liquids (ILs) [44] and deep eutectic solvents (DES) [45] have been introduced as "greener" alternatives in this field.

The first description of ILs dates to 1914, when Paul Walden reported the physical properties of ethyl ammonium nitrate $\left(\left[\mathrm{EtNH}_{3}\right]\left[\mathrm{NO}_{3}\right]\right)$ when testing new explosives for the replacement of nitroglycerin [46]. Nowadays, ILs are described as all organic salts with melting temperatures below $100^{\circ} \mathrm{C}$, being usually composed of a large organic cation and an organic or inorganic anion. The large dimensions of their ions and the high charge dispersion do not support their organization in an organized crystal structure, and as such, ILs are liquid at lower tem- 
peratures than conventional inorganic salts. Due to their ionic character, most aprotic ILs present unique characteristics, namely negligible flammability and volatility, high ionic conductivity, high thermal stability and a strong solvation capability for a large variety of compounds $[47,48]$. However, one of the most promising features of ILs is the ability to design their physico-chemical properties by a fine customization of the cation and/or anion chemical structure, being often referred to as designer solvents. This way, it is possible to tailor their polarity and selectivity in extraction/separation processes, as well as their biodegradability and toxicological impact $[46,49,50]$. Resulting from the described advantageous characteristics, these solvents have been investigated to improve many biological and chemical processes, namely in synthesis, (bio)catalysis, extraction/separation processes, electrochemistry and analytical applications (Figure 10.4) [51, 52]. The most widely studied ILs are composed of imidazolium-, pyridinium-, pyrrolidinium-, phosphonium- and tetraalkylammoniumbased cations, combined with anions such as chloride $\left(\mathrm{Cl}^{-}\right)$, bromide $\left(\mathrm{Br}^{-}\right)$, acetate $\left(\left[\mathrm{CH}_{3} \mathrm{CO}_{2}\right]^{-}\right)$, bis(trifluoromethylsulfonyl)imide $\left(\left[\mathrm{NTf}_{2}\right]^{-}\right.$ ) , hexafluorophosphate $\left(\left[\mathrm{PF}_{6}\right]^{-}\right)$and tetrafluoroborate $\left(\left[\mathrm{BF}_{4}\right]^{-}\right)[53]$. Figure 10.4 depicts the chemical structure of common IL cations and anions and their main applications. However, it should be remarked that the research focused on ILs is moving towards less toxic and more biodegradable formulations, mainly derived from natural sources [54, $55]$. 


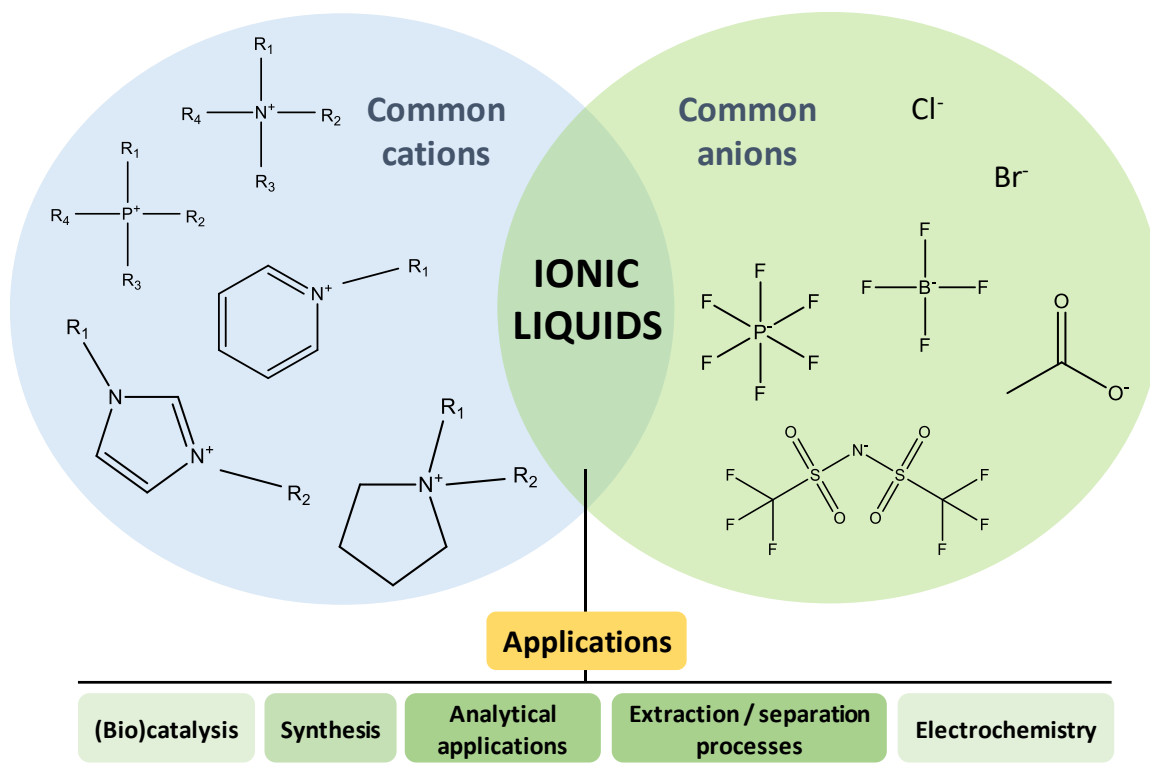

Fig. 10.4. Common cations and anions that form ILs and possible applications of these solvents.

In addition to ILs, in more recent years, deep eutectic solvents (DES) have emerged as promising alternatives over the typically used volatile organic solvents [56]. DES were first reported in 2001 by Abott et al. [57], and since then a growing interest in these solvents has been witnessed [58]. DES consist of a mixture of an hydrogen bond acceptor (HBA) and an hydrogen bond donor (HBD) species, which present a melting point significantly lower than that of the individual components. Beyond eutectic mixtures, DES do not follow the behavior of an ideal mixture since strong hydrogen-bond interactions are established between both compounds, leading to a significant decrease in the mixture melting temperature. Figure 10.5 provides several examples of HBAs and HBDs and an example of the solid-liquid phase diagram according to the DES composition [56]. 


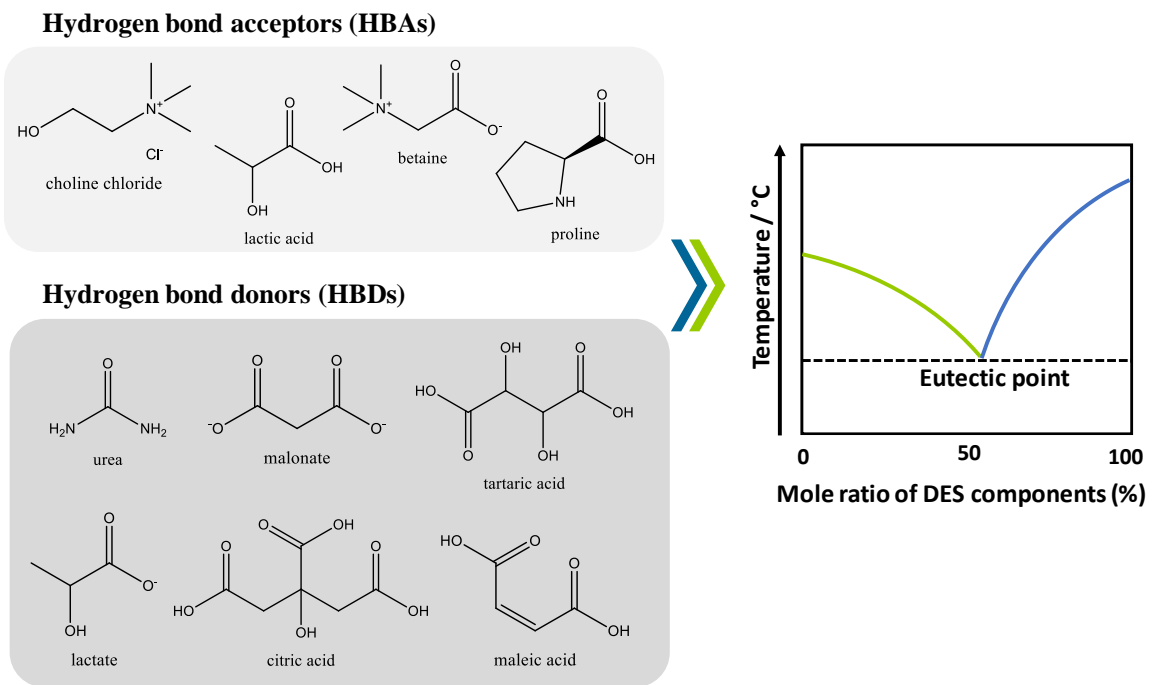

Fig. 10.5. Examples of HBAs and HBDs used in DES preparation and solid-liquid phase diagram representation of a DES.

As ILs, DES are commonly referred to as tunable solvents since a wide range of HBDs and HBAs species can be combined. However, DES present several advantages over ILs, such as their easy preparation (no chemical reaction required) and easy availability of the individual components, which are usually less expensive and from natural sources, such as amino acids, organic acids, sugars and cholinium derivatives. On the other hand, DES are often reported as less chemically inert than ILs [59]. Similarly to ILs, DES have found applications in a broad range of domains, spanning from catalysis, organic synthesis, biotechnology-related applications, among others [43, 45, $56,58]$. 
Based on the potential of ILs and DES as alternative solvents, in this chapter, sample pretreatment strategies proposed in recent years making use of these solvents are reviewed, namely on their use to allow the environmental monitoring of a large variety of pollutants from real matrices. The major drawbacks found and future perspectives are also given. Figure 10.6 summarizes the present work.

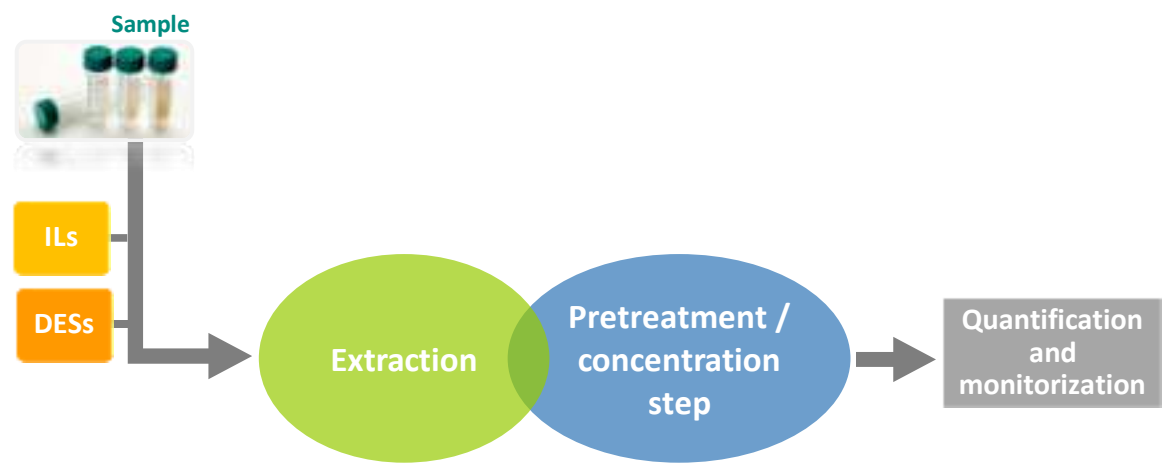

Fig. 10.6. Outline of the information presented in the current chapter, focused on the use of ILs and DES in extraction and/or pretreatment/preconcentration steps for trace-level pollutants quantification in real matrices. 


\section{Application of ionic liquids in the pretreatment step of real matrices to monitor trace-level pollutants}

The low concentration of pollutants in environmental samples represents the major challenge associated to their identification and accurate quantification [60]. In this sense, and as previously described, several sample pretreatment techniques have been implemented to extract and preconcentrate these contaminants before subjecting them to analytical quantification [41, 60]. Among those techniques, liquidliquid extraction (LLE) and solid-phase extraction (SPE) are the most explored [61-66]. In recent years, several microextraction methods, namely solid-phase microextraction (SPME) and dispersive liquidliquid microextraction (DLLME), have also been developed to improve the pretreatment procedure, while reducing the amount of solvents used and generating less residues [58]. Figure 10.7 summarizes the microextraction contributions within the Green Analytical Chemistry field.

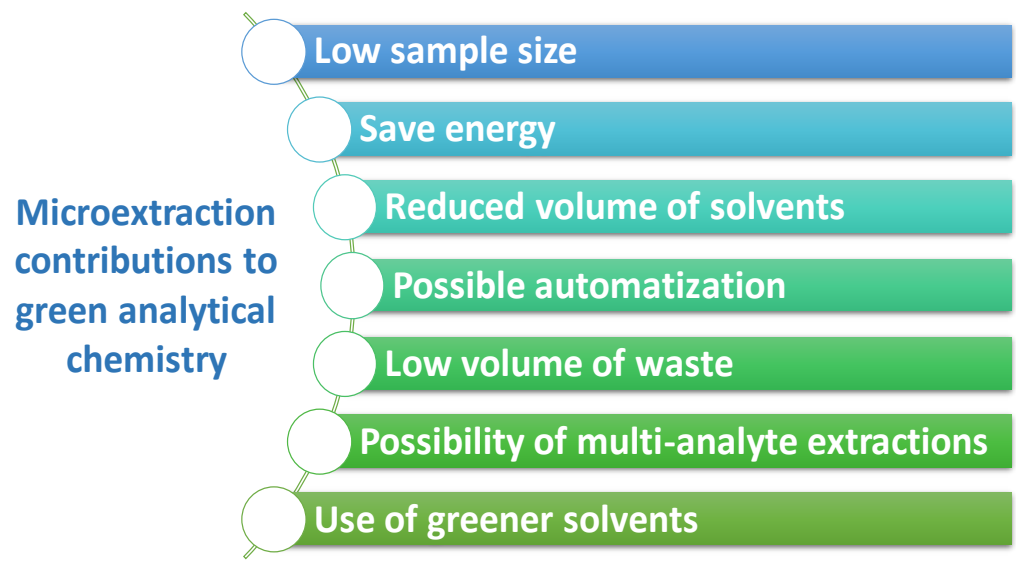

Fig. 10.7. Microextraction contributions to greener pretreatment steps. 
In this sub-chapter the most recent trends regarding the use of ILs in the pretreatment of environmentally-related samples are reviewed and discussed. In particular, it is described and discussed the application of ILs to improve the identification and quantification of heavy metals, endocrine disruptors, APIs, pesticides, PAHs, aromatic amines, UV filters components, and other organic pollutants. Table 1 summarizes the information reviewed in this sub-chapter, namely the target pollutant, as well as the yield, type of matrix, IL-based process used, preconcentration/enrichment factor, analytical method applied and limit of detection (LOD). Table 2 lists the ILs that are considered in this sub-chapter, comprising their names and corresponding chemical structures and acronyms. The next sub-chapters are grouped according to the type of pollutants. 
Table 1 - Summary of the information related to the use of ILs in pretreatment steps of real matrices to monitor environmental pollutants, describing the target analyte, pretreatment process, solvent, yield, type of matrix, enrichment factor, analytical equipment and limit of detection.

\begin{tabular}{|c|c|c|c|c|c|c|c|c|}
\hline $\begin{array}{l}\text { Target } \\
\text { analyte }\end{array}$ & $\begin{array}{c}\text { Pretreatment } \\
\text { process }\end{array}$ & $\begin{array}{c}\text { Pretreatment } \\
\text { solvent }\end{array}$ & Yield (\%) & Type of matrix & $\begin{array}{c}\text { Enrichment } \\
\text { factor }\end{array}$ & $\begin{array}{l}\text { Analytical } \\
\text { equipment }\end{array}$ & $\begin{array}{c}\text { LOD } \\
\left(\mu \mathrm{g} \cdot \mathbf{L}^{-1}\right)\end{array}$ & Reference \\
\hline \multicolumn{9}{|c|}{ Pharmaceuticals and endocrine disruptors } \\
\hline $\begin{array}{l}\text { Ciprofloxacin, en- } \\
\text { rofloxacin and norflox- } \\
\text { acin } \\
\text { Diclofenac, naproxen } \\
\text { and ketoprofen }\end{array}$ & $\mathrm{ABS}_{1}$ & {$\left[\mathrm{~N}_{4444}\right] \mathrm{Cl}$} & $\approx 100$ & Wastewater & 1000 & HPLC-DAD & $\mathrm{NR}_{2}$ & [37] \\
\hline $\begin{array}{l}\text { Paracetamol, ibuprofen, } \\
\text { naproxen and diclo- } \\
\text { fenac }\end{array}$ & MSPE3 & {$\left[\mathrm{C}_{4} \mathrm{mim}\right]\left[\mathrm{PF}_{6}\right]$} & $85-116$ & $\begin{array}{l}\text { Tap, dam and } \\
\text { river water }\end{array}$ & $29-34$ & HPLC-UV-FL & $3.2-7.2$ & [36] \\
\hline $\begin{array}{c}\text { Caffeine, } \\
\text { carbamazepine }\end{array}$ & ABS & {$\left[\mathrm{N}_{4444}\right] \mathrm{Cl}$} & $95-100$ & $\begin{array}{l}\text { Wastewater and } \\
\text { surface water }\end{array}$ & 8259- 28595 & HPLC-UV & NR & {$[67]$} \\
\hline Amitriptyline & IDME4 & {$\left[\mathrm{C}_{6} \operatorname{mim}\right]\left[\mathrm{PF}_{6}\right]$} & NR & $\begin{array}{c}\text { Hospital } \\
\text { wastewater }\end{array}$ & 1100 & HPLC-UV & 4.0 & {$[68]$} \\
\hline Bisphenol A & ABS & $\begin{array}{l}{\left[\mathrm{N}_{1112 \mathrm{OH}}\right] \mathrm{Cl}} \\
{\left[\mathrm{C}_{2} \mathrm{mim}\right] \mathrm{Cl}}\end{array}$ & $\approx 100$ & $\begin{array}{l}\text { Human fluid } \\
\text { (urine) }\end{array}$ & 100 & HPLC-MS & NR & [30] \\
\hline
\end{tabular}

1 Aqueous biphasic systems

2 Not reported

3 Magnetic solid phase extraction

4 Immersed droplet microextraction 


\begin{tabular}{|c|c|c|c|c|c|c|c|c|}
\hline $\begin{array}{l}\text { Several drugs, hor- } \\
\text { mones, caffeine }\end{array}$ & DLLME5 & $\begin{array}{c}{\left[\mathrm{NH}_{2} \mathrm{C}_{6} \mathrm{mpyr}\right][\mathrm{FAP}]} \\
{\left[\mathrm{C}_{4} \mathrm{mim}\right]\left[\mathrm{NTf}_{2}\right]}\end{array}$ & $91-110$ & $\begin{array}{c}\text { Tap and } \\
\text { creek water }\end{array}$ & 93 & HPLC-UV/Vis & $0.1-55.1$ & [34] \\
\hline \multicolumn{9}{|c|}{ Pesticides } \\
\hline Triazine & DLLME & {$\left[\mathrm{C}_{8} \mathrm{mim}\right]\left[\mathrm{PF}_{6}\right]$} & $85-100$ & $\begin{array}{l}\text { River and } \\
\text { underground water; } \\
\text { wastewater }\end{array}$ & NR6 & HPLC-UV & $0.05-0.06$ & [69] \\
\hline Sulfonylurea & VA-DLLME7 & {$\left[\mathrm{C}_{6} \mathrm{mim}\right]\left[\mathrm{PF}_{6}\right]$} & $80-104$ & Wine & NR & HPLC-DAD8 & $\begin{array}{l}3.2-6.6 \\
(\text { given in } \\
\mu \mathrm{g} \cdot \mathrm{Kg}^{-1} \text { ) }\end{array}$ & [12] \\
\hline $\begin{array}{l}\text { Clothianidin, imidaclo- } \\
\text { prid, dinotefuran, thia- } \\
\text { cloprid }\end{array}$ & CIAME9 & {$\left[\mathrm{C}_{4} \mathrm{mim}\right]\left[\mathrm{PF}_{6}\right]$} & $86-100$ & Honey & 200 & HPLC-DAD & 0.01 & [70] \\
\hline $\begin{array}{l}\text { Disulfoton, famphur, } \\
\text { parathion, parathion- } \\
\text { methyl, phorate, sul- } \\
\text { fotep, thionazin and } \\
\text { thiethyl thiophosphate }\end{array}$ & DLLME & {$\left[\mathrm{C}_{4} \operatorname{mim}\right]\left[\mathrm{NTf}_{2}\right]$} & $97-113$ & $\begin{array}{l}\text { River, irrigation } \\
\text { and marshes water }\end{array}$ & NR & GC-MS & $0.005-0.016$ & [18] \\
\hline
\end{tabular}

5 Dispersive liquid-liquid microextraction

6 Not reported

7 Vortex-assisted dispersive liquid-liquid microextraction

8 Photodiode array detection

9 Cold-induced aggregation microextraction 


\begin{tabular}{|c|c|c|c|c|c|c|c|c|}
\hline $\begin{array}{l}\text { Phoxim, fenitrothion, } \\
\text { chlorpyrifos, phorate } \\
\text { and parathion }\end{array}$ & DLLME & {$\left[\mathrm{C}_{6} \mathrm{H}_{5} \operatorname{mim}\right]\left[\mathrm{NTf}_{2}\right]$} & $82.7-118.3$ & $\begin{array}{c}\text { Tap, rain and river } \\
\text { water }\end{array}$ & 339 & HPLC-UV & $0.01-1.00$ & [71] \\
\hline \multicolumn{9}{|c|}{ PAHs, UV filters and other organic compounds } \\
\hline $\begin{array}{c}\text { Polycyclic } \\
\text { aromatic hydrocarbons }\end{array}$ & DLLME & {$\left[\mathrm{C}_{8} \mathrm{mim}\right]\left[\mathrm{PF}_{6}\right]$} & $90.3-103.8$ & $\begin{array}{l}\text { Tap, bottled, foun- } \\
\text { tain, well, river wa- } \\
\text { ter, rainwater; } \\
\text { wastewater }\end{array}$ & $301-346$ & HPLC-FL & $\begin{array}{l}0.0001- \\
0.007\end{array}$ & [24] \\
\hline $\begin{array}{c}\text { Polycyclic } \\
\text { aromatic hydrocarbons }\end{array}$ & SBDLME10 & $\begin{array}{c}{\left[\mathrm{P}_{66614}\right][} \\
\left.\mathrm{Ni}(\mathrm{II})(\mathrm{hfacac})_{3}\right]\end{array}$ & $84-115$ & $\begin{array}{l}\text { River, tap and rain } \\
\text { water }\end{array}$ & $18-717$ & GC-MS & $\begin{array}{l}0.0005- \\
0.0087\end{array}$ & [72] \\
\hline $\begin{array}{l}\text { 2,4-dichloroaniline, } 1- \\
\text { naphthylamine, } 6 \text {-chlo- } \\
\text { roanline and } \mathrm{N}, \mathrm{N} \text {-dime- } \\
\text { thylaniline }\end{array}$ & USA-DLLME11 & {$\left[\mathrm{C}_{6} \mathrm{mim}\right]\left[\mathrm{PF}_{6}\right]$} & $92.2-119.3$ & $\begin{array}{c}\text { Melted snow water, } \\
\text { river and brook wa- } \\
\text { ter }\end{array}$ & $\mathrm{NR}_{12}$ & HPLC-UV & $0.17-0.49$ & [39] \\
\hline Organophosphate esters & SPME13 & {$\left[\mathrm{C}_{6} \mathrm{mim}\right][\mathrm{FAP}]$} & $82.1-123.0$ & $\begin{array}{l}\text { Tap water, sewage } \\
\text { treatment plant wa- } \\
\text { ter }\end{array}$ & $168-2603$ & GC-MS & $\begin{array}{l}0.0005- \\
0.024\end{array}$ & [40] \\
\hline
\end{tabular}

10 Stir bar dispersive liquid microextraction

11 Ultrasound-assisted dispersive liquid-liquid microextraction

12 Not reported

13 Solid-phase microextraction 


\begin{tabular}{|c|c|c|c|c|c|c|c|c|}
\hline $\begin{array}{l}\text { Benzophenone-type } \\
\text { UV filters }\end{array}$ & $\begin{array}{c}\text { USA- } \\
\text { DLLME }\end{array}$ & {$\left[\mathrm{C}_{6} \mathrm{mim}\right][\mathrm{FAP}]$} & $71-118$ & $\begin{array}{l}\text { River, swimming } \\
\text { pool and tap water }\end{array}$ & $354-464$ & HPLC-UV & $0.2-5.0$ & [73] \\
\hline $\begin{array}{l}\text { Benzophenone-type } \\
\text { UV filters }\end{array}$ & HF-LPME14 & {$\left[\mathrm{C}_{6} \mathrm{mim}\right][\mathrm{FAP}]$} & $82.6-105.9$ & River water & 216 & HPLC-UV & $0.3-0.5$ & [74] \\
\hline \multicolumn{9}{|c|}{ Heavy metals } \\
\hline Zinc & DLLME & {$\left[\mathrm{C}_{6} \mathrm{py}\right]\left[\mathrm{PF}_{6}\right]$} & $97.1-102.5$ & $\begin{array}{l}\text { Underground tap } \\
\text { and spring water; } \\
\text { milk }\end{array}$ & 71 & FAAS 15 & 0.22 & [26] \\
\hline
\end{tabular}

14 Hollow-fiber liquid-phase microextraction

15 Flame atomic absorption spectrometry 
Table 2 - ILs investigated in pretreatment strategies of environmental-related samples, comprising their names, acronyms and chemical structures.

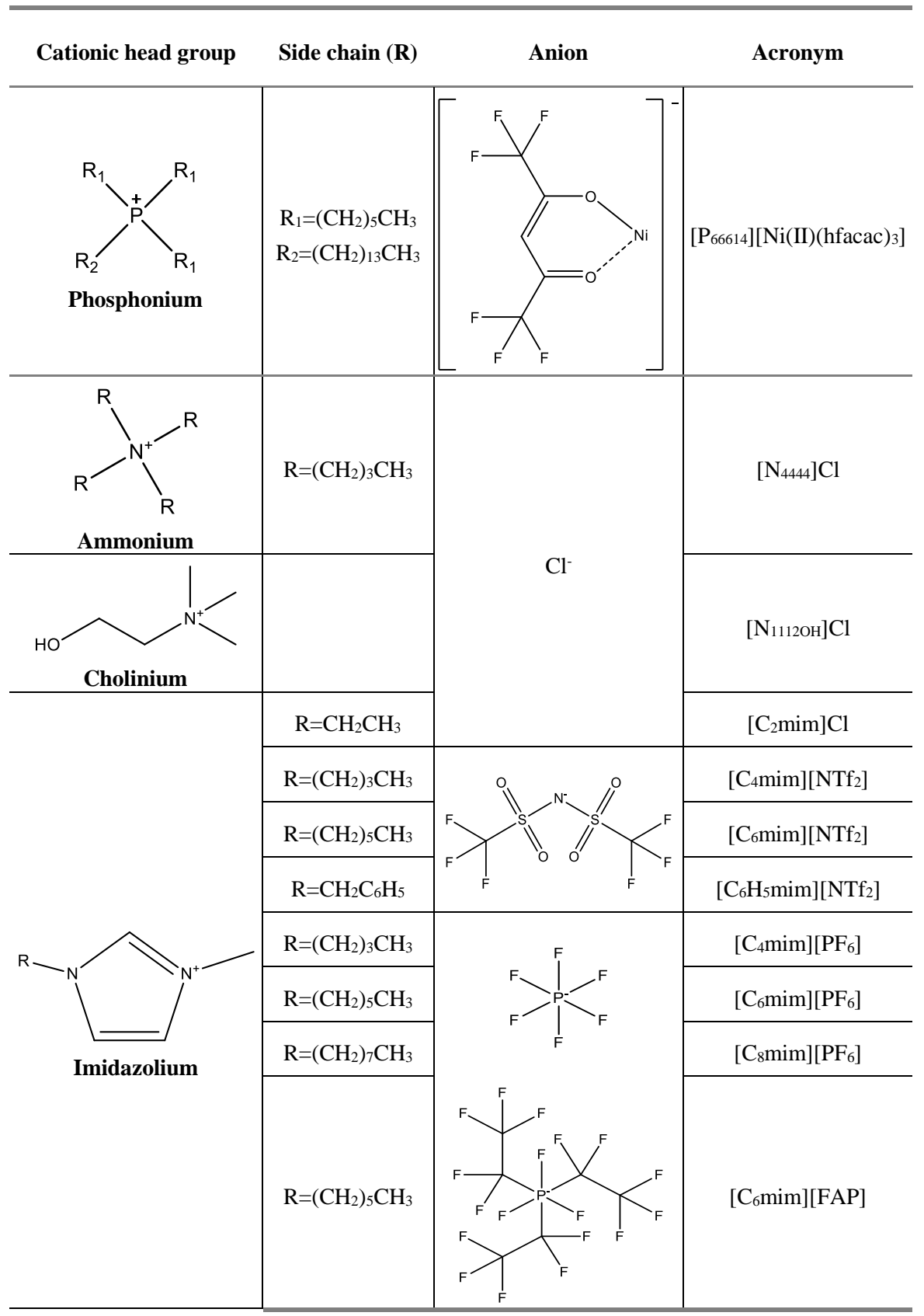




(2)

\subsection{Pharmaceuticals and endocrine disruptors}

Emerging public health concerns have significantly raised in recent years regarding the adverse effects of pharmaceuticals and endocrine disruptors. Some of these pollutants have been detected in wastewater, rivers, and even in drinking water [37]. In the field of environmental monitoring, ILs have been largely investigated. Pharmaceuticals such as fluoroquinolones (FQs) and other antibiotics, nonsteroidal anti-inflammatory drugs (NSAIDs), and endocrine disruptors, have been investigated. Aiming at improving their environmental monitoring, ILs such as $\left[\mathrm{P}_{4444}\right] \mathrm{Cl}$, [N $\left.\mathrm{N}_{444}\right] \mathrm{Cl},\left[\mathrm{C}_{4} \mathrm{mim}\right][\mathrm{FAP}]$, $\left[\mathrm{C}_{4} \mathrm{mim}\right]\left[\mathrm{NTf}_{2}\right],\left[\mathrm{C}_{4} \mathrm{mim}\right]\left[\mathrm{PF}_{6}\right]$ and $\left[\mathrm{C}_{6} \mathrm{mim}\right]\left[\mathrm{PF}_{6}\right]$ (see Table 2 for their chemical structures) have been used in pretreatment strategies. The pretreatment methods applied in this set of works correspond to the use of aqueous biphasic systems (ABS), dispersive liquid-liquid microextraction (DLLME), immersed droplet microextraction (IDME) and magnetic solid phase extraction (MSPE). 
Passos et al. [30], Almeida et al. [37] and Dinis et al. [67] proposed the application of one of the most promising liquid-liquid extraction (LLE) methods involving ILs found in the literature - aqueous biphasic systems (ABS) - to successfully extract and concentrate bisphenol A, ciprofloxacin, enrofloxacin, norfloxacin, diclofenac, naproxen, ketoprofen, caffeine and carbamazepine (Figure 10.8) from urine matrices, wastewater and surface water, aiming at improving their detection and quantification foreseeing an accurate environmental monitoring.

ABS are liquid-liquid systems and allow the extraction of target molecules from one aqueous phase to another. Usually, these systems are composed of several pairs of solutes dissolved in water (e.g. polymerpolymer, polymer-salt, polymer-IL, IL-salt, etc.), where above specific concentrations there is two-phase formation [48]. Mostly due to their large water content and non-volatile nature of the phase-forming components, these systems have been considered as sustainable liquid-liquid extraction options. The use of ILs as phase-forming components of ABS has been largely investigated in recent years [48]. This trend is due to the designer solvents ability of ILs, which is transposed to IL-based ABS, allowing the design of the phases' polarities and affinities, and thus high selectivity and extraction performance to be achieved $[46,48]$. A schematic representation of the ABS separation process and their use as pretreatment strategies is summarized in Figure 10.9. 


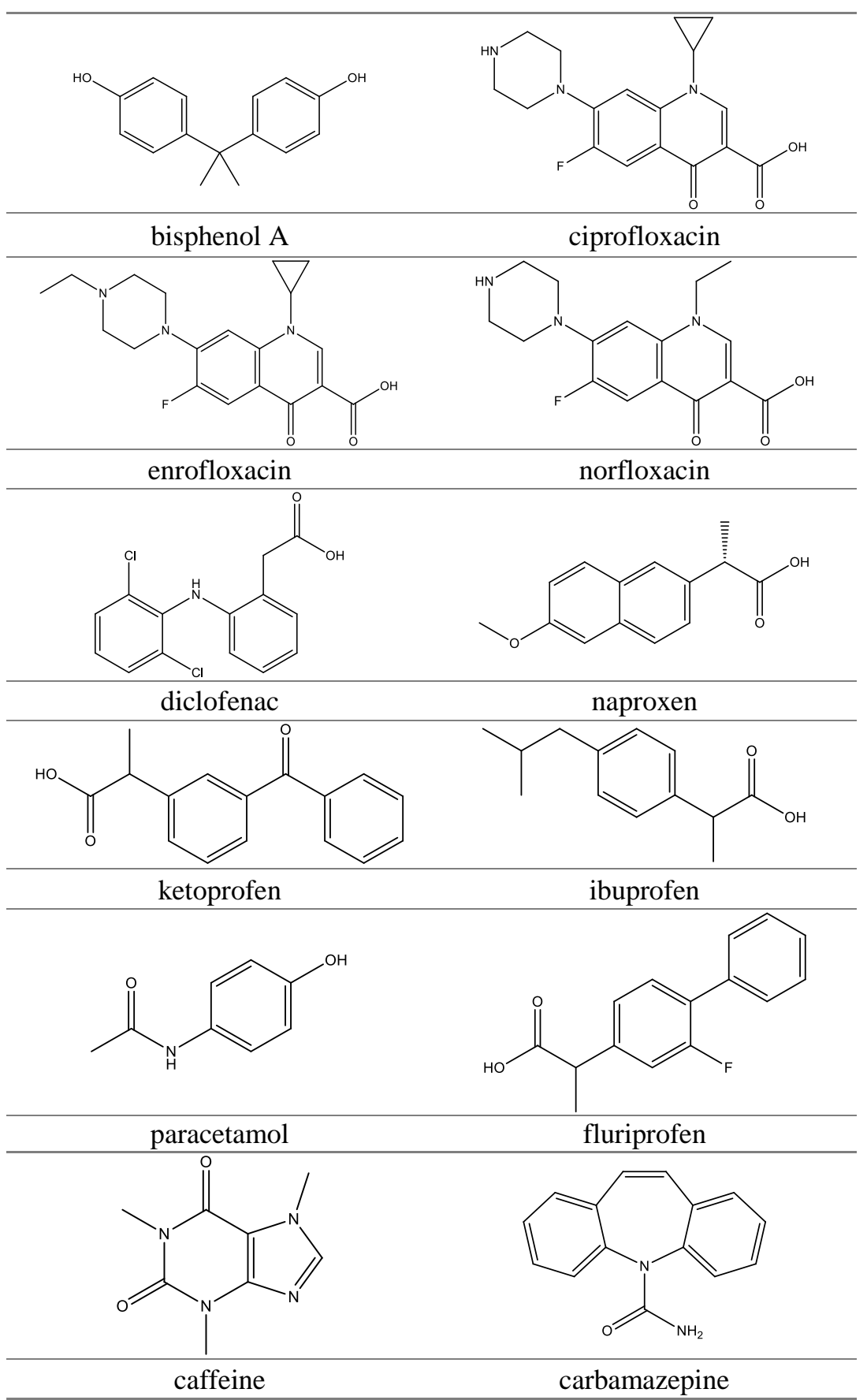

Fig. 10.8. Chemical structures of the investigated endocrine disruptors and pharmaceuticals. 

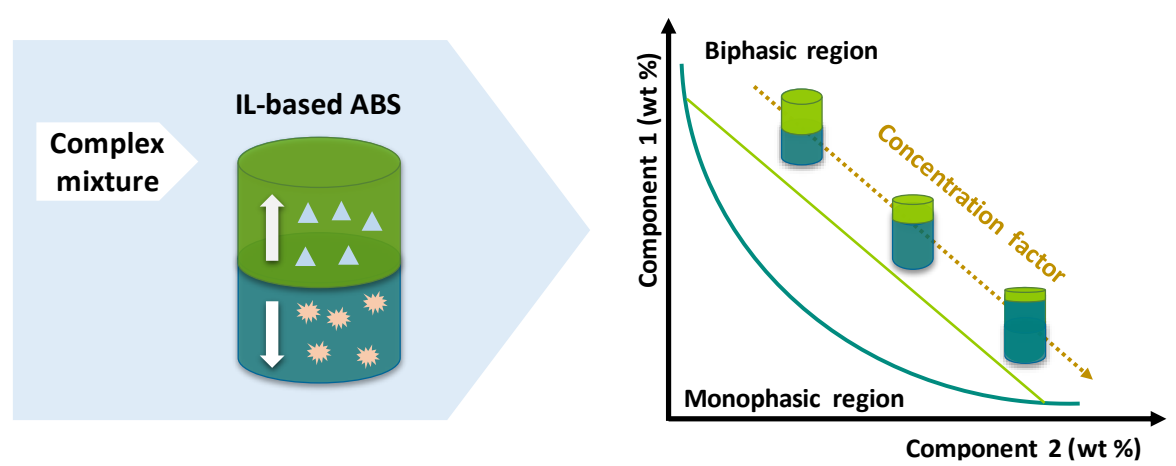

Fig. 10.9. Schematic illustration behind the use of IL-based ABS as pretreatment and concentration platforms.

Taking advantage of the ability of ABS to design their phases' polarities and affinities, Passos et al. [30] applied ABS composed of $\left[\mathrm{N}_{1112 \mathrm{OH}}\right] \mathrm{Cl}$ or $\left[\mathrm{C}_{2} \mathrm{mim}\right] \mathrm{Cl}$ and potassium phosphate to extract bisphenol A (Figure 10.8) from human urine, achieving a preconcentration factor of 100-fold in a single-step. Urine contains significant amounts of $\mathrm{NaCl}$ and urea, which the authors found as beneficial to improve the partitioning of bisphenol A to the IL-rich phase. The authors concluded that these systems require small amounts of IL and allow a reproducible and accurate quantification of bisphenol $\mathrm{A}$ in human fluids. Also taking advantage of the ABS tailoring ability, Almeida et al. [37] studied the single-step extraction and preconcentration of FQs and NSAIDs (Figure 10.8) using ABS composed of $\left[\mathrm{N}_{4444}\right] \mathrm{Cl}$ and a citrate-based salt $\left(\mathrm{C}_{6} \mathrm{H}_{5} \mathrm{~K}_{3} \mathrm{O}_{7}\right)$. This study described the recovery of three FQs (ciprofloxacin, enrofloxacin and norfloxacin) and three NSAIDs (diclofenac, naproxen and ketoprofen) from real effluent samples from wastewater treatment plants. The proposed 
systems allowed to achieve preconcentration factors of 1000 -fold of both FQs and NSAIDs and extraction efficiencies of these APIs close to $100 \%$ towards the IL-rich phase, without reaching the saturation of the IL-rich phase [35]. This enrichment factor allowed their direct identification and quantification by high-performance liquid chromatography (UV-HPLC). Dinis et al. [67] also applied IL-based ABS to extract and concentrate caffeine and carbamazepine from wastewater effluents and surface water samples. Based on the solubility of each pollutant in the IL-rich phase, the authors concluded that the investigated IL-based ABS may allow enrichment factors of 28595 and 8259-fold, respectively, and extraction efficiencies of both tracers to the IL-rich phase ranging between 95 and 100\%, in a single step [67]. Overall, it is important to stress the ability of these systems to simultaneously extract and concentrate several pollutants without saturating the IL-rich phase at the levels at which they are found in the environment, allowing the analytical quantification without major interferences of the ABS phase-forming components [67].

DLLME is a pretreatment strategy of relevant interest for the preconcentration/enrichment of a wide range of compounds. This technique is a simple, sustainable and low-cost procedure. In DLLME, the cloudy state is created due to the solvent droplets upon injection of the binary solvent mixture, known as extraction and disperser solvents, into an aqueous sample. The large surface area between the fine droplets and the aqueous phase promotes the transfer of analytes from the sample solution into the extraction phase. Usually, a centrifugation step is further applied causing the sedimentation of the droplets 
at the bottom of the tube (typically of conical shape), being this phase collected using a syringe and further analysed by the appropriate analytical technique [75]. In this solvent-minimizing technique, only a few microliters of a selected solvent are used to extract analytes in comparison to the large amount of volatile organic solvents often required in traditional LLE. Figure 10.10 summarizes the experimental steps required in DLLME. The type of extraction and disperser solvents, and their volumes, significantly affects the DLLME extraction efficiency and enrichment factors.

Taking advantage of the benefits of DLLME coupled to ILs, Yao et al. [34] proposed the use of functionalized ILs containing the tris(perfluoroalkyl)trifluorophosphate anion ([FAP]) in DLLME for the extraction of 14 emerging contaminants (APIs, hormones, caffeine and endocrine disruptors, whose chemical structures are shown in [32]) from water samples. All ILs investigated are immiscible with water and can thus be directly used in DLLME, contrarily to ABS where water-miscible ILs are used requiring the addition of a third component (usually a salt) to create two phases. Compounds containing functionalized tertiary amines are preferentially extracted by $\left[\mathrm{NH}_{2} \mathrm{C}_{6} \mathrm{mpyr}\right][\mathrm{FAP}]$ in comparison to other [FAP]-based ILs. On the other hand, polar or acidic compounds without amine groups display higher enrichment factors using $\left[\mathrm{C}_{4} \mathrm{mim}\right]\left[\mathrm{NTf}_{2}\right]$. Real water samples including tap water and creek water were analyzed, yielding recoveries ranging from $91 \%$ to $110 \%$. The LOD varied from 0.1 to 55.1 $\mu \mathrm{g}^{\prime} \mathrm{L}^{-1}$ using the [ $\mathrm{NH}_{2} \mathrm{C}_{6}$ mpyr][FAP] IL as extraction solvent [34]. 


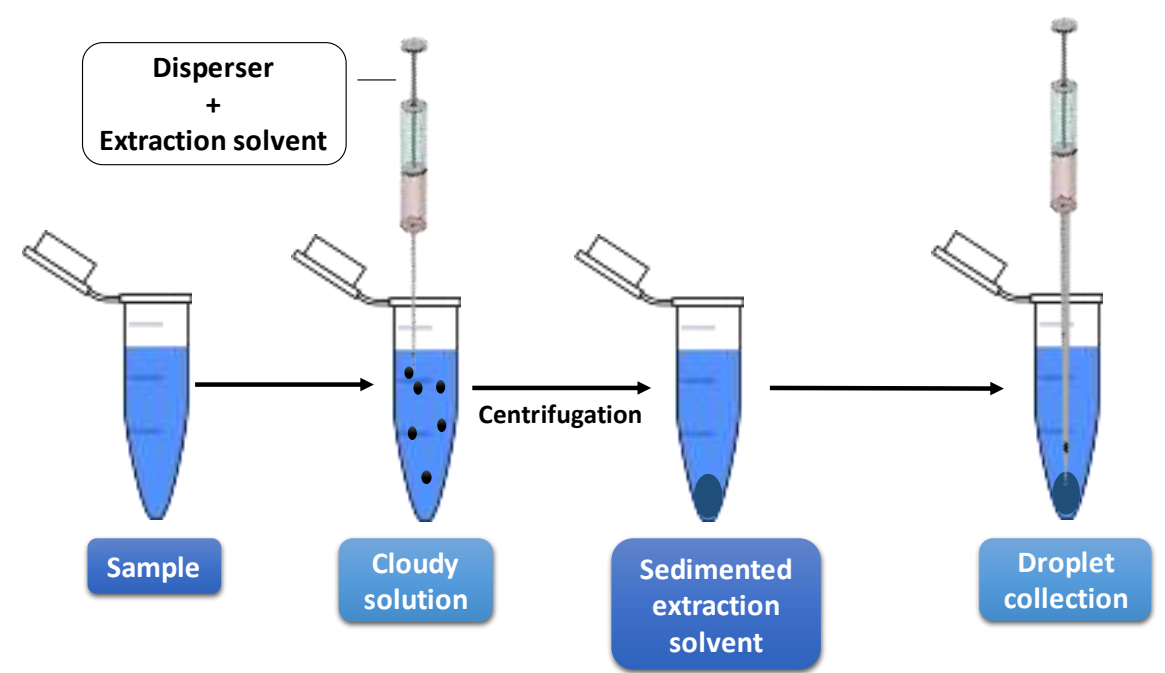

Fig. 10.10. Schematization of the DLLME process.

Furthermore, since a single operational step is required, in this technique there is less contamination and less loss of analytes compared to conventional solvents extractions. Although both DLLME and conventional extraction methods exhibit similar recoveries, DLLME allows higher enrichment factors [76].

Abujaber et al. [36] and Mosavian et al. [68] proposed different approaches for the identification and quantification of several pharmaceuticals, such as paracetamol, ibuprofen, naproxen and diclofenac (Figure 10.8) in natural waters, and amitriptyline (Figure 10.8) in hospital wastewater, respectively. Abujaber et al. [36] used magnetic cellulose nanoparticles (MCNPs) coated with $\left[\mathrm{C}_{4} \mathrm{mim}\right]\left[\mathrm{PF}_{6}\right]$, by electrostatic interactions, as new sorbents for magnetic solid phase extractions (MSPE). A schematic representation of the experimental procedure proposed is shown in Figure 10.11. The authors studied the influence of several parameters that may affect adsorption (type of 
dispersive solvent, amount of IL, $\mathrm{pH}$ and salt content) and desorption (type of desorption solvent, energy and time) steps to optimize the process. The proposed method provides enrichment factors ranging from 29.0 to 34.2 , and extraction recoveries ranging between 85 and $116 \%$. Using HPLC with UV and fluorescence (FL) detectors as the analytical method, LODs of $11-24 \mu \mathrm{g} \cdot \mathrm{L}^{-1}$ were reported. Since the modification of the magnetic nanoparticles occurs by non-covalent interactions, namely by electrostatic interactions, the leaching of the IL should be taken into account. Despite the low water-solubility of $\left[\mathrm{C}_{4} \mathrm{mim}\right]\left[\mathrm{PF}_{6}\right]$ at room temperature, it is still significant and may contaminate water streams [77]. Mosavian et al. [68] proposed the use of the same IL for the monitoring of amitriptyline (Figure 10.8) in wastewater by IL-based immersed droplet microextraction (IDME) prior to HPLC-UV analysis. In IDME, the sample solution is added to a glass vial containing a magnetic bar, and then, a fine IL droplet is immersed into the stirred aqueous solution using a micro syringe and collected from the bottom of the vial. A pre-concentration factor of 1100 and a LOD of $0.004 \mathrm{mg} \mathrm{mL}^{-1}$ were reported by the authors. The authors also performed a comparative analysis between the proposed method, conventional liquid-liquid extractions and DLLME, concluding that the proposed IL-based IDME allows the highest enrichment factor while avoiding organic solvents use [68]. 
28

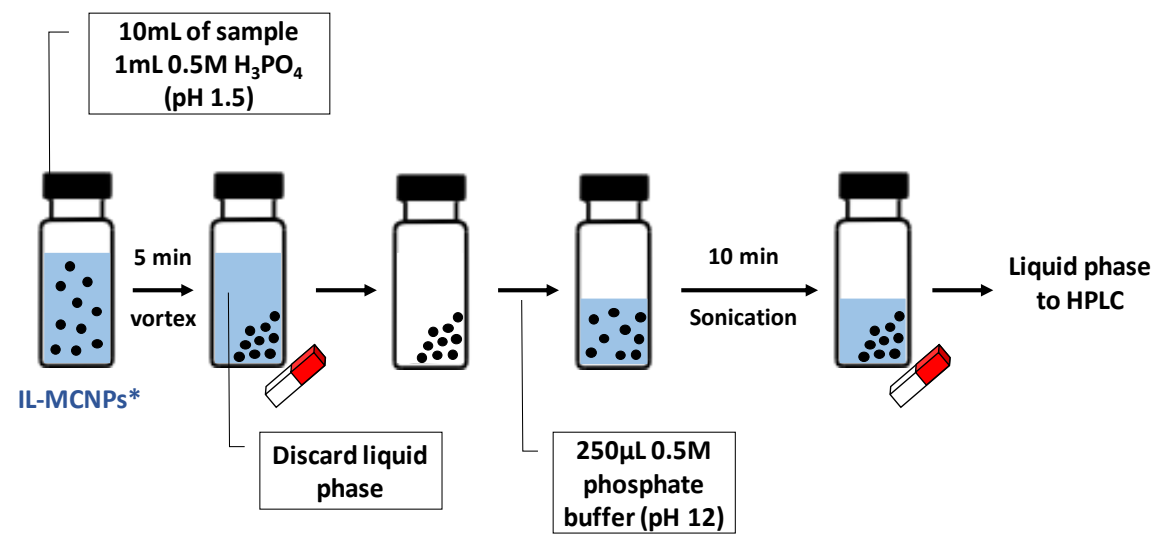

* 50mg MCNPs $+150 \mu \mathrm{L}$ mixture of $\left[\mathrm{C}_{4} \mathrm{mim}\right]\left[\mathrm{PF}_{6}\right](50 \mu \mathrm{L})$ and $\mathrm{MeOH}(100 \mu \mathrm{L})$

Fig. 10.11. Schematic representation of the analytical method.

\subsection{Pesticides}

There are several reports on the use of ILs in microextraction processes, namely DLLME and cold-induced aggregation microextraction (CIAME), to monitor the levels of pesticides [12, 18, 69, 70], whose structures are displayed in Figure 10.12. This kind of research is mandatory since these pollutants constitute a major anthropogenic source. In this vein, Zhou et al. [69] reported a temperature-controlled DLLME using $\left[\mathrm{C}_{8} \mathrm{mim}\right]\left[\mathrm{PF}_{6}\right]$ as the extraction solvent in combination with HPLC-UV, to enrich extracts in triazine herbicides, namely cyanazine, simazine, and atrazine (Figure 10.12) from four real water samples. Under the optimal conditions ( $\mathrm{pH}$, centrifugation time, temperature and ionic strength), recoveries between $85.1-100 \%$ and LOD in the range from 0.05 to $0.06 \mathrm{mgL}^{-1}$ were obtained [69]. 


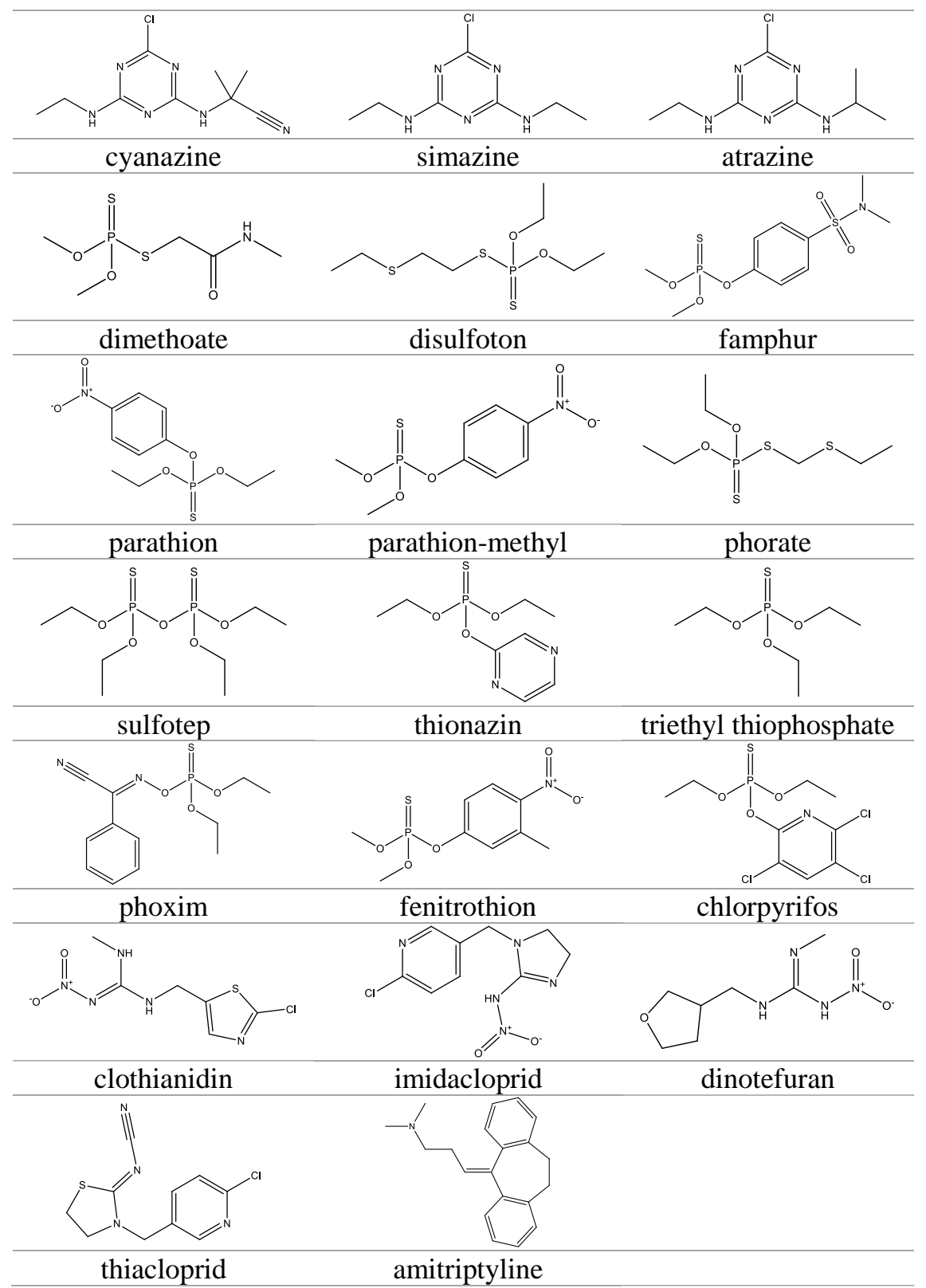

Fig. 10.12. Chemical structures of the studied pesticides.

Cacho et al. [18] also focused their studies in DLLME, in which the IL extracting phase was placed in a glass micro vial inside the thermal 
desorption tube. The whole assembly was submitted to a temperature program in the thermal desorption unit. As soon as the IL is heated, the target analytes are vaporized, and a carrier gas impels them to the programmed temperature vaporization injector where they are concentrated before entering the chromatographic column. Since ILs possess negligible vapor pressures, the IL matrix remains in the disposable glass micro vial after the heating step $[18,29]$. This procedure allows the direct introduction of the IL extracts into the GC apparatus, simplifying the process while increasing sensitivity and accuracy. Moreover, under optimal conditions (temperature, time and gas flow rate) the authors demonstrated the accurate determination of nine organophosphorus pesticides (disulfoton, famphur, parathion, parathion-methyl, phorate, sulfotep, thionazin and thiethyl thiophosphate - Figure 10.12) from environmental waters. In this work, the use of $\left[\mathrm{C}_{4} \mathrm{mim}\right]\left[\mathrm{NTf}_{2}\right]$ led to recoveries in the $85-118 \%$ range and to a LOD ranging from 0.005 to $0.016 \mu \mathrm{g}^{-1} \mathrm{~L}^{-1}[18]$. Taking into account that the proper functionalization of ILs could enhance the extraction efficiency of the target compounds, Wang et al. [71] proposed the use of a benzyl functionalized IL $\left(\left[\mathrm{C}_{6} \mathrm{H}_{5} \mathrm{mim}\right]\left[\mathrm{NTf}_{2}\right]\right)$ as the extraction solvent in DLLME for the analysis of 5 organophosphorus pesticides (phoxim, fenitrothion, chlorpyrifos, phorate and parathion - Figure 10.12) in environmental water samples by HPLC-UV. The introduction of the benzyl group into the imidazolium cation significantly increases the extraction efficiency, which may be due to $\pi{ }^{\prime \prime} \pi$ interactions occurring between the IL and the target aromatic compounds. The extraction was performed using $40 \mu \mathrm{L}$ of $\left[\mathrm{C}_{6} \mathrm{H}_{5} \mathrm{mim}\right]\left[\mathrm{NTf}_{2}\right]$ and 
$1 \mathrm{~mL}$ of methanol as dispersive solvent, with a centrifugation time of $5 \mathrm{~min}$. Under the optimal conditions, an enrichment factor of 339, recoveries ranging between $81.4 \%$ and $118.3 \%$ and LODs ranging from 0.01 to $1.0 \mu \mathrm{g} \cdot \mathrm{L}^{-1}$ were reported [71].

In addition to the previous works, some authors focused their studies on strategies that, along with the miniaturization of the process, improve the dispersion of hydrophobic ILs into the aqueous samples. In this context, several DLLME derivative techniques were proposed, such as vortex-assisted dispersive liquid-liquid microextraction (VADLLME), air-assisted dispersive liquid-liquid microextraction (AALLME) and ultrasound-assisted dispersive liquid-liquid microextraction (USA-DLLME). Gure et al. [12] suggested the application of VA-DLLME, followed by capillary liquid chromatography for the determination of four sulfonylurea herbicides in wine samples. The IL $\left[\mathrm{C}_{6} \mathrm{mim}\right]\left[\mathrm{PF}_{6}\right]$ was used as extraction solvent and was dispersed using methanol into the sample solution, assisted by a vortex mixer. Under the optimum conditions (type and amount of IL, type and volume of disperser solvent, $\mathrm{pH}$, salting-out effect, vortex and centrifugation time), recoveries higher than $80 \%$ and LODs ranging between 3.2 and $6.6 \mu \mathrm{g} \cdot \mathrm{Kg}^{-1}$ were reported [12].

To eliminate the interface between water and the extractant phases, while removing drawbacks from mass transfer effects, cold-induced aggregation microextraction (CIAME) techniques have been developed. The hydrophobic components are preferentially collected by the extraction solvent in fine droplets, and the solution is cooled in an ice bath, forming a cloudy solution. Subsequently, the resulting emulsion 
32

can be completely separated by centrifugation. Usually, CIAME is a simple and accurate preconcentration technique applied for the analysis of samples containing high concentration of salts and water miscible organic solvents. Vichapong et al. [70] proposed a preconcentration approach based on IL-based CIAME before the analysis of the samples by HPLC with a photodiode array detector (HPLC-DAD) to detect neonicotinoid insecticides (clothianidin, imidacloprid, dinotefuran, thiacloprid) in honey samples. The chemical structures of these insecticides are depicted in Figure 10.12. [ $\left.\mathrm{C}_{4} \mathrm{mim}\right]\left[\mathrm{PF}_{6}\right]$ was used as the extraction solvent and sodium dodecyl sulphate (SDS) as the surfactant. Optimum microextraction conditions were attained, leading to enrichment factors of 200 , recoveries above $86 \%$, and LOD of 0.01 $\mu \mathrm{g}^{\cdot} \mathrm{L}^{-1}$ for all analytes.

\subsection{Polycyclic aromatic hydrocarbons, UV filters and other} organic compounds

Along with the pollutants discussed before, there are other classes of compounds that deserve equal prominence in environmental monitoring, namely PAHs, aromatic amines, organophosphate esters and UV filters (chemical structures given in Figure 10.13). In this section, several extraction methods, such as DLLME, stir bar dispersive liquid microextraction (SBDLME), USA-DLLME, SPME and hollow-fiber

DLLME for the accurate quantification of these types of pollutants are overviewed and discussed. 


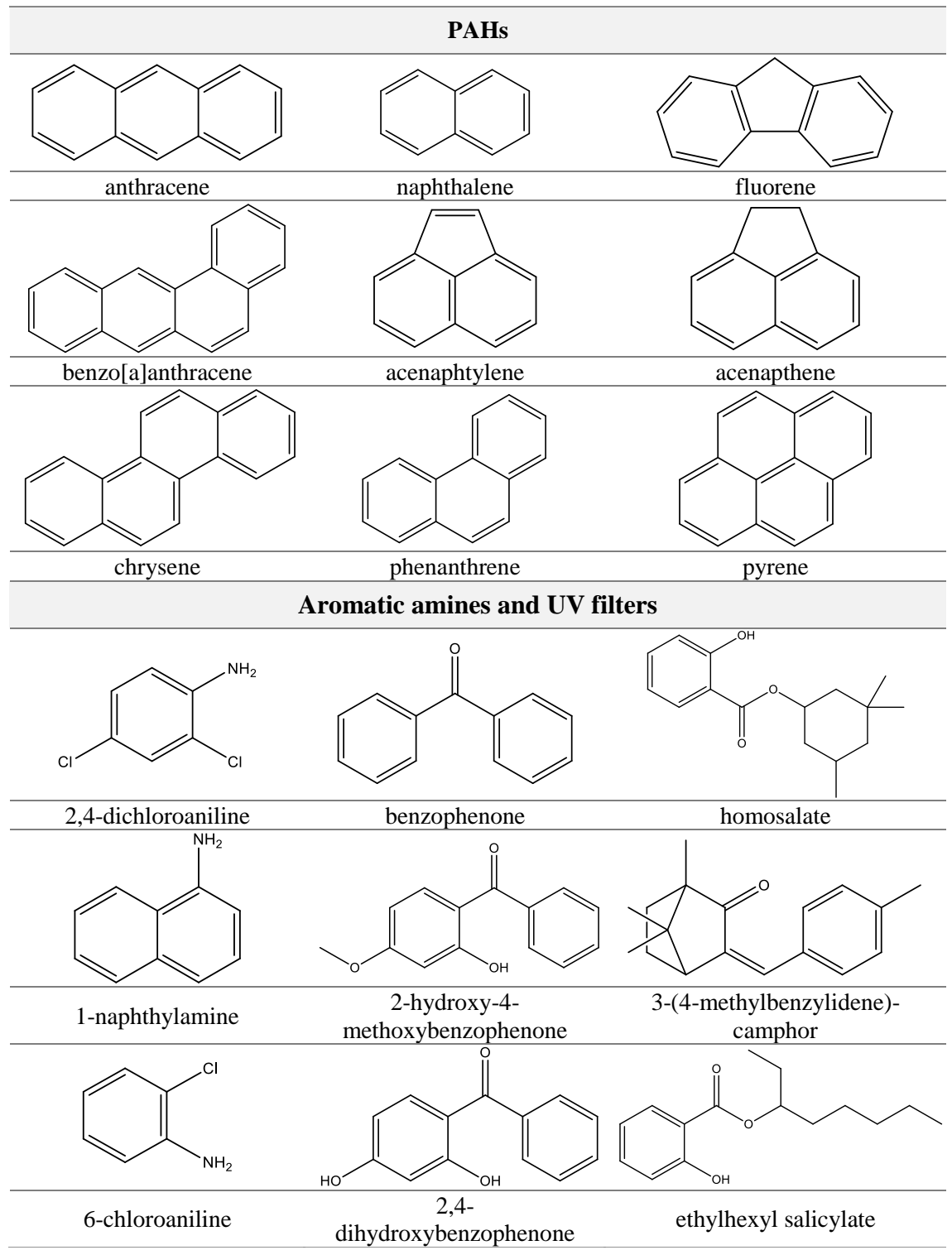

Fig. 10.13. Schematic representation of some of the studied PAHs, aromatic amines and UV filters. 
PAHs are ubiquitous environmental pollutants primarily generated during the incomplete combustion of organic materials (e.g. coal, oil, petrol, and wood), which are associated to toxic and/or carcinogenic properties. Aiming an accurate monitoring of PAHs, Pena et al. [24] explored the application of IL-based DLLME for the analysis of 18 PAHs (Figure 10.3) - such as naphthalene, acenaphtylene, acenapthene, fluorene, phenanthrene, anthracene, pyrene, benzo[a]anthracene anc crysene - from water samples, namely tap, bottled, fountain,

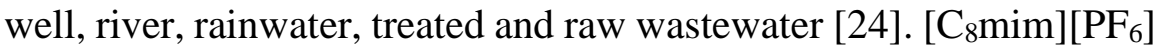
was used to take advantage of the chemical affinity between this IL and PAHs, allowing the simultaneous extraction and preconcentration from the original samples. Factors affecting the extraction efficiency and enrichment factor (type and volume of IL, type and volume of disperser solvent, extraction time, centrifugation time and ionic strength) were investigated by the authors. High enrichment factors (301-346) and extraction yields, ranging from $90.3 \%$ to $103.8 \%$, were obtained. The authors further evaluated the effect of the nature of the water samples, showing that the recovery of PAHs undergoes a progressive reduction with the increasing complexity of the water samples. For instance, with treated wastewater and raw wastewater, a decrease of $40 \%$ and $60 \%$ in the recovery efficiency, respectively, was found. This trend was attributed to the presence of colloidal organic matter in the samples. The authors also demonstrated that IL-based DLLME provides similar recoveries for all PAHs compared to con- 
ventional LLE. However, the proposed procedure is more advantageous since it is faster,;simple and smaller volumes of organic solvents are applied [24].

Benedé et al. [72] explored an innovative hybrid approach called stir bar dispersive liquid microextraction (SBDLME) (Figure 10.14), which combines the advantages of stir bar absorptive extraction (SBSE) and dispersive liquid-liquid microextraction (DLLME) for the determination of 10 PAHs, being the most significant ones described in Figure 10.13, from tap, rain and river water samples. The extraction was performed using a neodymium stir bar magnetically coated with a magnetic ionic liquid (MIL) as extraction device. In this technique, the $\left[\mathrm{P}_{66614}\right]\left[\mathrm{Ni}(\mathrm{II})(\mathrm{hfacac})_{3}\right]$ is dispersed into the solution at high stirring rates. Once the stirring is over, the MIL is magnetically retrieved and further subjected to thermal desorption, being directly applied into GC-MS. This method allows enrichment factors between 18 and 717, recovery values ranging from 84 to $115 \%$ and LOD ranging from 0.0005 to $0.0087 \mathrm{ngL}^{-1}$. Furthermore, the authors carried out a comparative analysis of the proposed SBDLME method with other approaches coupled to GC-MS for the same purpose, verifying a similar analytical performance. Moreover, it is important to point out that the combination of both SBSE and DLLME into the new approach offers an improvement in the versatility and selectivity of the method, mostly due to the low availability of commercial sorbents and the ability to design extraction phases depending on the target analytes. Although the MIL reuse is limited compared to other sorbent-based 
phases, the MIL could be recovered by soaking in an appropriate solvent. Alternatively, the MIL could be recovered and purified by electrodialysis [72]. Despite the ability to reuse the extraction phase/MIL, it is important to assess the pros and cons of this technique since organic solvents may be required to allow the MIL reusability.

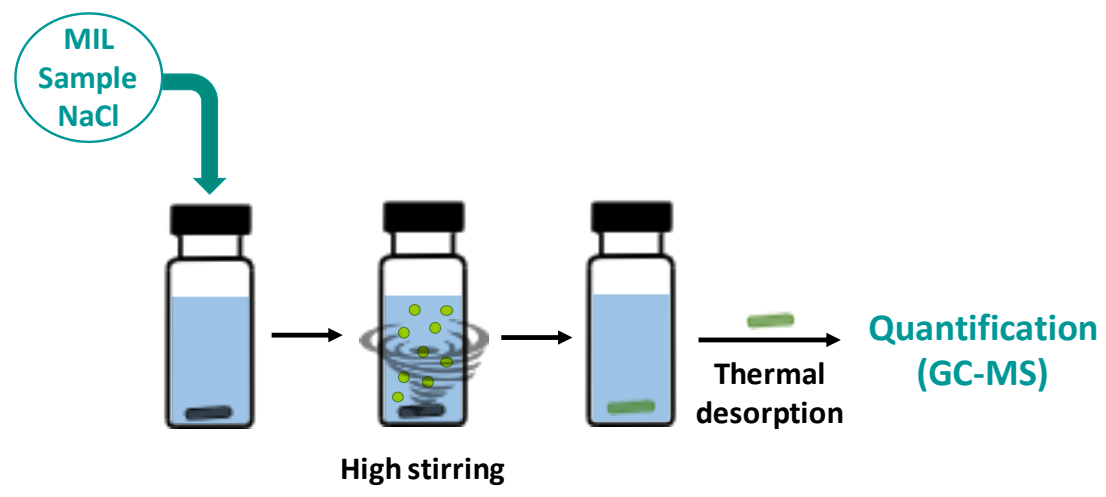

Fig. 10.14. Schematic representation of the SBDLME technique.

Aromatic amines are emerging environmental pollutants, which are included in the list of priority pollutants by the US Environmental Protection Agency. Their environmental persistence is due to their use as intermediates in the manufacturing of several compounds (pesticides, rubbers, adhesives, pharmaceuticals and engine lubricants). Most aromatic amines are extensively toxic and carcinogenic [39], being mandatory their proper monitoring. With this goal in mind, Zhou et al. [39] reported the application of USA-DLLME using ILs for the determination of aromatic amines from real water samples, namely 2,4-dichloroaniline, 1-naphthylamine and 6-chloroaniline 
(Figure 10.13) by HPLC-UV. The IL $\left[\mathrm{C}_{6} \mathrm{mim}\right]\left[\mathrm{PF}_{6}\right]$ was used, being dispersed in the aqueous sample solution as fine droplets by ultrasonication, while promoting the easy migration of the analytes into the IL-rich phase. In order to optimize the extraction of these target pollutants into the IL droplets, several variables were investigated, such as the volume of the IL, sample $\mathrm{pH}$, ultrasonication time, extraction time and centrifugation time. The proposed method allows recoveries in the range of $92.2-119.3 \%$ and a LOD in the range of $0.17-0.49$ $\mu \mathrm{g} \cdot \mathrm{L}^{-1}$ [39].

The monitorization of organophosphate esters is particularly relevant since these compounds are widely used as flame-retardants, plasticizers, hydraulic fluid, antifoaming agents, lubricants, floor covering, and lacquer/paint/glue [40]. Based on this scenario, Shi et al. [40] applied the IL $\left[\mathrm{C}_{6} \mathrm{mim}\right][\mathrm{FAP}]$ as a coating fluid in SPME (Figure 10.15) aiming at extracting 11 organophosphate esters, which are described in [40], from real environmental water samples. In this work, the fiber was assembled by coating a stainless-steel wire with $\left[\mathrm{C}_{6} \mathrm{mim}\right][\mathrm{FAP}]$ using a dip-coating approach. The analysis was carried out by gas chromatography coupled to mass spectrometry (GC-MS). The established SPME (Figure 10.15) exhibits an excellent selectivity and sensitivity towards the extraction and analysis of organophosphate esters from real aqueous samples, such as tap water, and influent and effluent of sewage treatment plants. The proposed SPME method allows to obtain recoveries between 82.1 and $123 \%$, enrichment factors varying between 168 and 2603, and LODs ranging from 0.50 to 24.0 
$\mathrm{ng} \cdot \mathrm{L}^{-1}$. The reported $\left[\mathrm{C}_{6} \mathrm{mim}\right][\mathrm{FAP}]$-based SPME coating demonstrated long-term stability, showing no loss of the IL-coatings or reduction of extraction efficiency after at least 65 cycles of use [40].
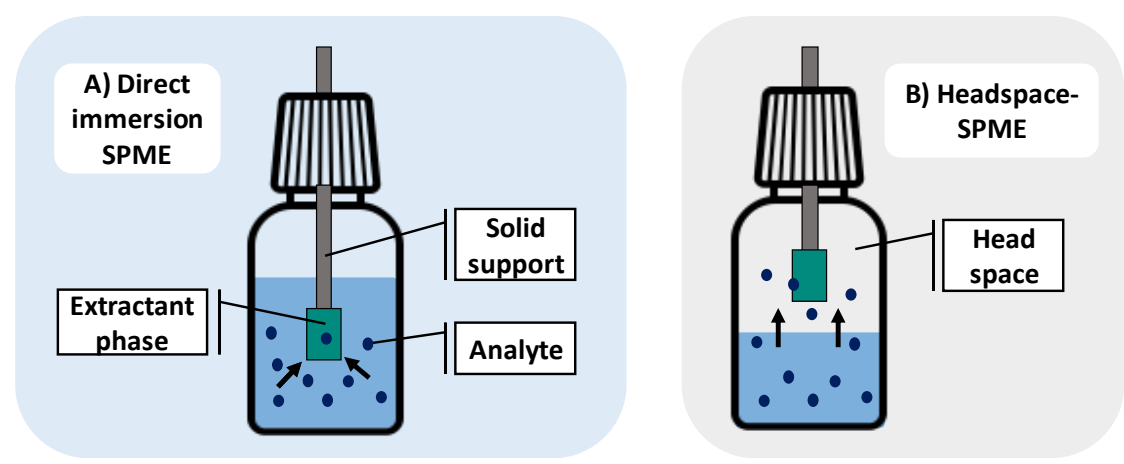

Fig. 10.15. Schematic representation of the SPME technique (A) Direct immersion and B) Head space).

UV filters are present in a wide range of personal care products and cosmetics. As consequence, a significant amount of UV filters enters directly into surface water. The nature of these compounds lead to significant bioaccumulation and biomagnification along the food chain [78]. As such, their monitoring is extremely important. Zhang et al. [73] and Ge et al. [74] focused their studies in the detection of UV filters components (Figure 10.13) in real environmental waters. The two groups of researchers presented two different approaches for the same purpose; however, both used the same IL ([C $\left.\left.\mathrm{C}_{6} \mathrm{mim}\right][\mathrm{FAP}]\right)$. This IL was chosen due to its high chemical affinity to the target analytes, thereby allowing the selective isolation of UV filters from the aqueous matrix. 
Zhang et al. [73] suggested the application of USA-DLLME to extract and preconcentrate four benzophenone-type UV filters (benzophenone, 2-hydroxy-4-methoxybenzophenone, ethylhexyl salicylate and homosalate - Figure 10.13). The reported method is based on a ternary solvent system containing small droplets of IL in the aqueous sample solution formed by dissolving an appropriate amount of the IL ([ $\left.\left.\mathrm{C}_{6} \mathrm{mim}\right][\mathrm{FAP}]\right)$ in methanol (water-miscible dispersive solvent). Then, an ultrasound-assisted step is performed to enhance the formation of a cloudy solution, which markedly increases the extraction efficiency, while reducing the equilibrium time. Several parameters that may affect the extraction efficiency were evaluated, namely type and volume of extraction and dispersive solvents, ionic strength, $\mathrm{pH}$ and extraction time. Under optimal conditions and depending on the analytes, enrichment factors in the range from 354 to 464 were obtained, with LODs ranging from $0.2-5.0 \mu \mathrm{g} \cdot \mathrm{L}^{-1}$ and recoveries ranging from $71.0 \%$ to $118.0 \%$ [73]. On the other hand, Ge et al. [74] proposed the application of hollow-fiber liquid-phase microextraction (HF-LPME) to determine UV filters (benzophenone, 3-(4-methylbenzylidene)-camphor, 2-hydroxy-4-methoxybenzophenone and 2,4-dihydroxybenzophenone - Figure 10.13). In this technique, a hollow fiber containing the extraction solvent is fixed in the tip of a syringe needle for the extraction of analytes from an aqueous sample. Then, the extraction solvent is withdrawn into the syringe and injected into the analytical system (HPLC-UV) (Figure 10.16). Overall, HF-LPME utilizes a hollow fiber to stabilize the extraction solvent, and the small pore size of the fiber prevents large molecules from entering into the 
acceptor phase, resulting in the cleanup of the sample during the extraction step. Ge et al. [74] reported that HF-LPME coupled to HPLCUV provides recoveries ranging from $82.6 \%$ to $105.9 \%$ and LODs ranging between 0.3 and $0.5 \mathrm{ng} \cdot \mathrm{mL}^{-1}$. Despite the environmental burden, this method can be automated, presenting a great advantage over other DLLME techniques that require intensive hand work.

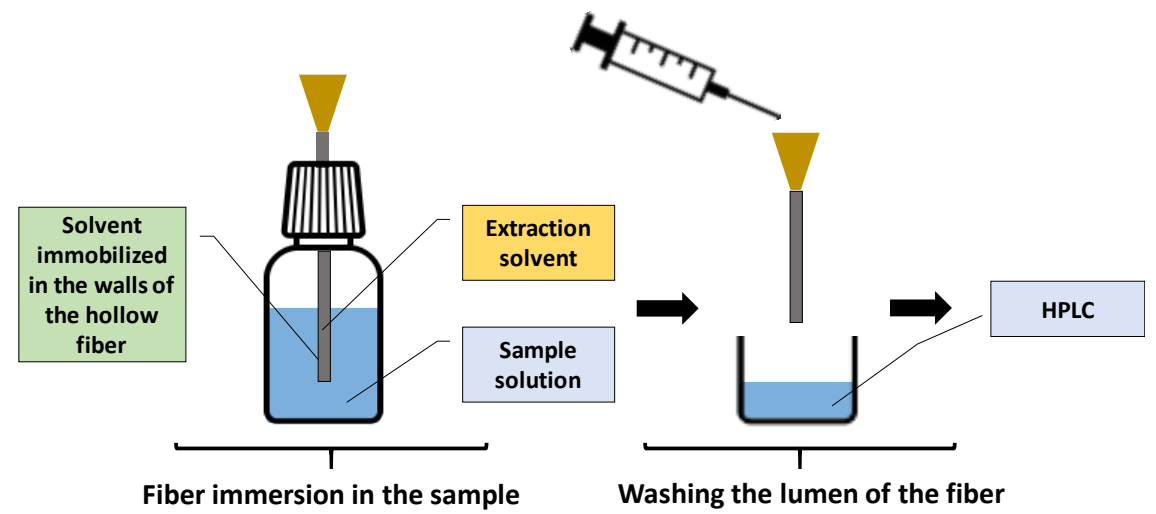

Fig. 10.16. Schematic representation of the HF-DLLME technique.

\subsection{Heavy metals}

Heavy metals are priority compounds of public health concern. Their domestic, agricultural and technological applications have led to their broad distribution in the environment, increasing the awareness over their hazardous effects on both human health and the environment. Regarding the quantification of metals present both in water and food products, Abdolmohammad-Zadeh et al. [26] explored the application of DLLME using $\left[\mathrm{C}_{6} \mathrm{py}\right]\left[\mathrm{PF}_{6}\right]$ as an extractant solvent for the preconcentration of zinc from water and milk samples, quantified by flame atomic absorption spectrometry (FAAS). Zinc was complexed 
with 8-hydroxyquinoline and extracted into the selected IL, with a LOD of $0.22 \mu \mathrm{g} \mathrm{L}^{-1}$ and an enrichment factor of 71 . The authors stressed that the sensitivity of the method could be further increased by using graphite furnace atomic absorption spectroscopy (GF-AAS) as the detection method [26]. Although GF-AAS leads to a more timeconsuming process, the sample volume is lower, which could be advantageous from a sustainable point of view.

Overall, ILs have been used in several pretreatment methods to improve the detection and quantification of several classes of trace-level pollutants. However, the proposed methods should be tested with several types of environmental matrices and in the analysis of a broader range of compounds, with the goal of finding an IL-based pretreatment strategy that could be broadly applied.

\section{Application of DES in the pretreatment step of trace- level pollutants from real matrices}

Green technology is steadily searching for novel solvents able to replace organic solvents which display inherent toxicity. The green character of ILs is often questioned, mainly due to the poor biodegradability and biocompatibility of the most studied ILs. It should be however remarked that "greener" ILs can be indeed used if a proper selection of the cation/anion chemical structures is carried out. DES have been described as a more sustainable alternative to ILs, mainly because they are prepared from natural-derived compounds and be- 
cause there is no need of a synthesis/reaction step. Based on their potential, in this sub-chapter the most recent trends regarding the use of DES in environmental monitoring procedures will be discussed. This subchapter is particularly focused on the application of several DES, mostly cholinium-based ones, for the quantification of trace-level pollutants (PAHs, aromatic amines, active pharmaceuticals, pesticides and heavy metals) using several analytical techniques (solvent extraction, DLLME, AALLME, LPME and SPME). Table 3 compiles the information reviewed in this sub-chapter, namely the target pollutant, as well as the yield, type of matrix, DES-based process used, preconcentration/enrichment factor, analytical method applied and limit of detection (LOD). Table 4 lists the DES that are considered in this subchapter, comprising their names and corresponding chemical structures of their components and acronyms. It should be however remarked that the use of DES for the pretreatment of environmental samples is still in its infancy, and as such, a significant lower number of works is discussed in this sub-chapter.

Since works dealing with solid samples requiring a digestion step have been found (e.g. vegetables, fish, etc.), the following discussion is divided according to the type of samples (liquid versus solid samples), as schematized in Figure 10.17. 


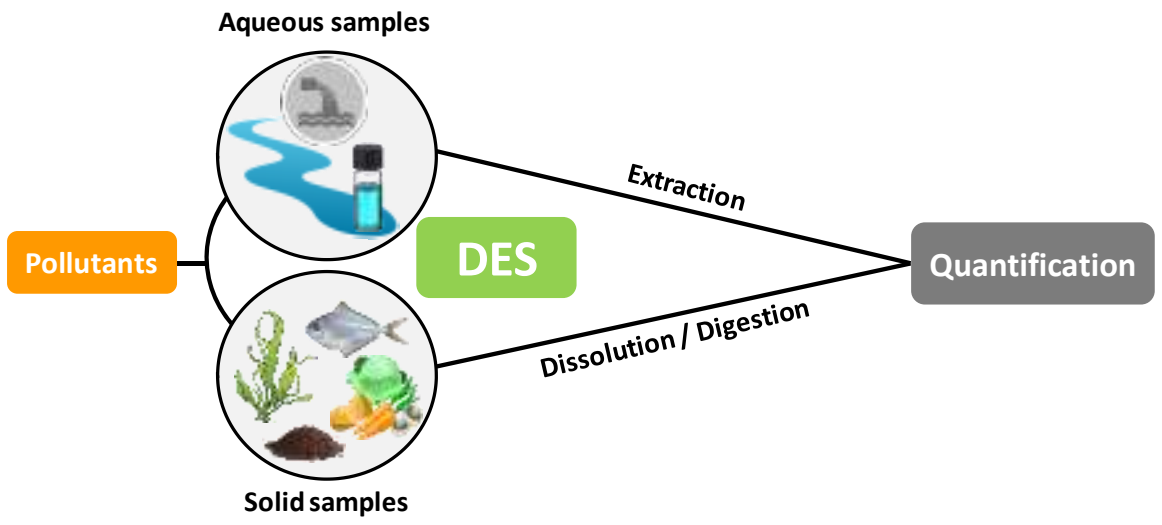

Fig. 10.17. Outline of the studies discussed in the present sub-chapter, focused on the use of DES in the extraction and/or digestion/dissolution processes. 
Table 3 - Summary of the information related to the use of DES in pretreatment steps of real matrices to monitor environmental pollutants, describing the target analyte, pretreatment process, pretreatment solvent, yield, type of matrix, enrichment factor, analytical equipment and limit of detection.

\begin{tabular}{|c|c|c|c|c|c|c|c|c|}
\hline $\begin{array}{c}\text { Target } \\
\text { Analytes }\end{array}$ & $\begin{array}{l}\text { Pretreatment } \\
\text { process }\end{array}$ & $\begin{array}{c}\text { Pretreatment } \\
\text { solvent }\end{array}$ & Yield (\%) & Type of matrix & $\begin{array}{l}\text { Enrichment } \\
\text { factor }\end{array}$ & $\begin{array}{l}\text { Analytical equip- } \\
\text { ment }\end{array}$ & $\begin{array}{c}\text { LOD } \\
\left(\mu g L^{-1}\right)\end{array}$ & Reference \\
\hline \multicolumn{9}{|c|}{ Active pharmaceutical ingredients (APIs) } \\
\hline $\begin{array}{l}\text { Ketoprofen, flurbi- } \\
\text { profen, diclofenac }\end{array}$ & $\begin{array}{c}\text { Solid-phase } \\
\text { microextraction }\end{array}$ & $\begin{array}{c}\text { Cholinium chloride: } \\
\text { itaconic acid } \\
(3: 2)\end{array}$ & $84.5-111.2$ & Lake water & 100 & HPLC-UV & $0.05-0.5$ & {$[35]$} \\
\hline \multicolumn{9}{|c|}{ PAHs } \\
\hline $\begin{array}{l}\text { Phenanthrene, an- } \\
\text { thracene, fluoran- } \\
\text { thene, pyrene, among } \\
\text { others }\end{array}$ & USA-DLLME1 & $\begin{array}{l}\text { Thymol:camphor } \\
(1: 1)\end{array}$ & $73.5-126.2$ & $\begin{array}{l}\text { Effluent from } \\
\text { bitumen } \\
\text { production }\end{array}$ & $\mathrm{NR}_{2}$ & GC-MS & $0.0039-0.0098$ & [22] \\
\hline $\begin{array}{l}\text { Naphthalene, bi- } \\
\text { phenyl, acenaph- } \\
\text { thylene, fluorene, } \\
\text { fluoranthene, anthra- } \\
\text { cene, among others }\end{array}$ & $\begin{array}{l}\text { Organic (diges- } \\
\text { tion/dissolution) }\end{array}$ & $\begin{array}{l}\text { Cholinium chloride: } \\
\text { oxalic acid } \\
(1: 2)\end{array}$ & 71.6-109.6 & $\begin{array}{c}\text { Fish, } \\
\text { macroalgae }\end{array}$ & NR & HPLC-FL & $\begin{array}{c}0.0005- \\
0.00308 \\
(\mu \mathrm{g} / \mathrm{g})\end{array}$ & [23] \\
\hline
\end{tabular}

1 Ultrasound-assisted dispersive liquid-liquid microextraction

2 Not reported 


\begin{tabular}{|c|c|c|c|c|c|c|c|c|}
\hline \multicolumn{9}{|c|}{ Aromatic amines } \\
\hline $\begin{array}{c}\text { Aniline, p-toluidine, } \\
\text { p-chloroaniline,p- } \\
\text { anisidine, among } \\
\text { others }\end{array}$ & AALLME3 & $\begin{array}{l}\text { Cholinium chloride: } \\
\text { n-butyric acid }\end{array}$ & $79-94$ & $\begin{array}{l}\text { Tap, surface and } \\
\text { river water; } \\
\text { wastewater }\end{array}$ & $790-940$ & GC-MS & $0.0018-0.023$ & [79] \\
\hline \multicolumn{9}{|c|}{ Pesticides } \\
\hline $\begin{array}{c}\text { Diazinon, metalaxyl, } \\
\text { bromopropylate, } \\
\text { oxadiazon, fena- } \\
\text { zaquin }\end{array}$ & $\begin{array}{l}\text { Liquid-phase mi- } \\
\text { croextraction }\end{array}$ & $\begin{array}{c}\text { Cholinium chloride: } \\
\text { p-chlorophenol } \\
(1: 2)\end{array}$ & $56-93$ & $\begin{array}{c}\text { Juice; } \\
\text { vegetables }\end{array}$ & NR & GC-FID & $0.13-0.31$ & [17] \\
\hline \multicolumn{9}{|c|}{ Heavy metals } \\
\hline $\mathrm{Cu}, \mathrm{Zn}, \mathrm{Fe}$ & $\begin{array}{l}\text { Digestion/ } \\
\text { dissolution }\end{array}$ & $\begin{array}{l}\text { Cholinium chloride: } \\
\text { oxalic acid } \\
(1: 2)\end{array}$ & $>95$ & Fish & NR & $\mathrm{FAAS}_{4}$ & $6-53$ & [27] \\
\hline $\mathrm{Hg}, \mathrm{Pb}, \mathrm{Cd}$ & DLLME5 & $\begin{array}{l}\text { 1-octyl-3-methylimid- } \\
\text { azolium chloride : 1- } \\
\text { undecanol } \\
(1: 2)\end{array}$ & $91-110$ & $\begin{array}{c}\text { Soil and } \\
\text { vegetables }\end{array}$ & $114-172$ & GFAAS6 & $\begin{array}{c}0.01-0.03 \\
(\mu \mathrm{g} / \mathrm{kg})\end{array}$ & [29] \\
\hline
\end{tabular}

3 Air-assisted dispersive liquid-liquid microextraction

4 Flame atomic absorption spectrometry

5 Dispersive liquid-liquid microextraction

6 Graphite furnace atomic absorption spectrometry 
Table 4 - DES investigated in pretreatment strategies of environmental-related samples, comprising their names, acronyms and chemical structures.

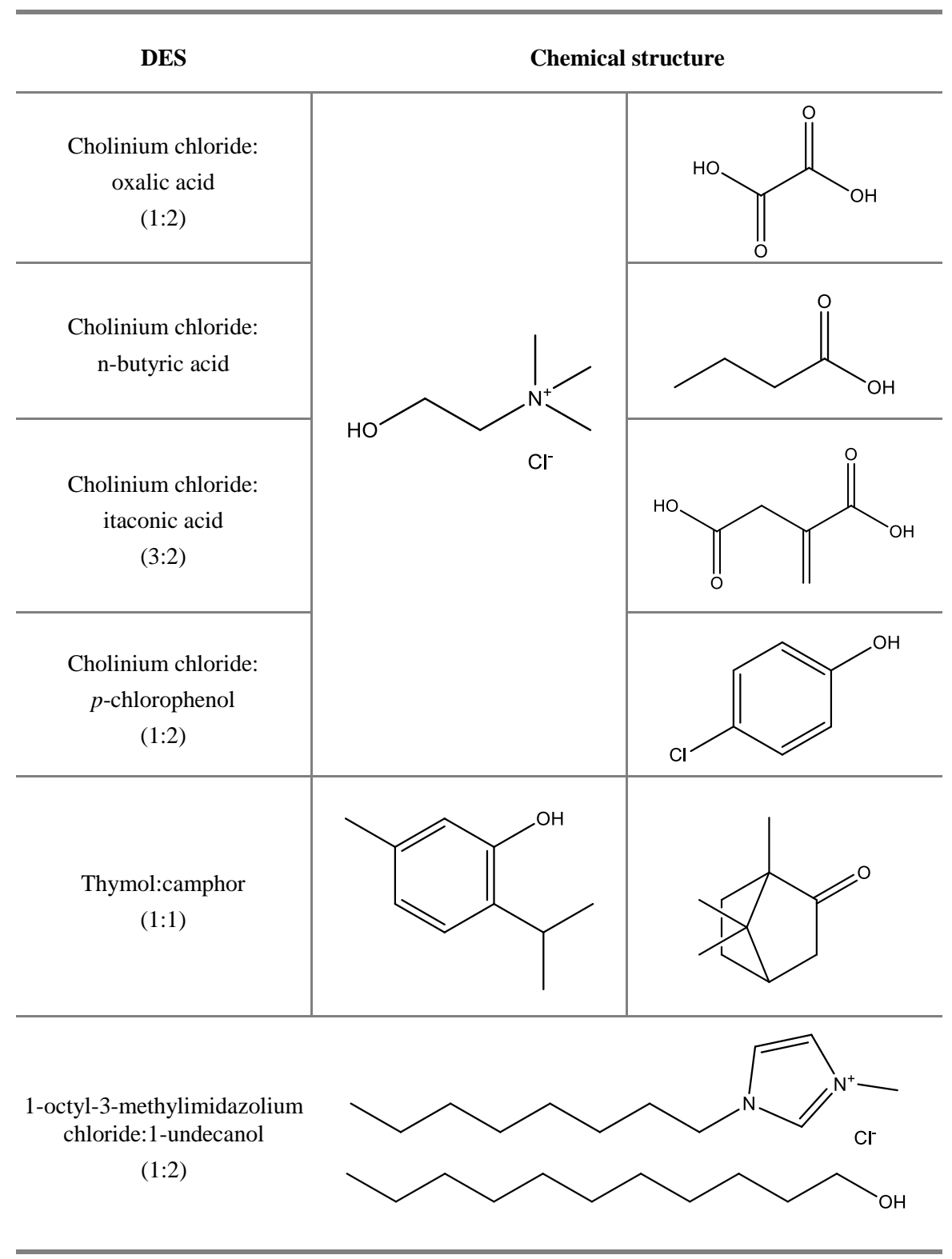


Regarding the monitoring of environmental pollutants in aqueous sample solutions, Wang et al. [35] proposed an innovative in-tube SPME of three NSAIDs - ketoprofen, fluriprofen, diclofenac - (Figure 10.8) from lake water samples. The DES composed of cholinium chloride and itaconic acid (3:2) was used as a functional monomer to synthesize a polymeric monolith inside polydopamine-functionalized poly(ether ether ketone) (PEEK) tube. The modification of the inner wall surface of the PEEK tube using dopamine and 3-(triethoxysilyl)propyl methacrylate ( $\gamma$-MAPS) was firstly carried out, followed by the polymerization reaction including the DES previously prepared. Under the optimized conditions, an online SPME-HPLC method was created by connecting the PEEK tube to the HPLC-UV system. By this approach, it was possible to obtain enrichment factors of ca. 100 and recoveries above $87 \%$. The major advantage of this procedure is that by changing the composition of DES, different polymer sorbent properties can be explored and applied in the extraction of other compounds. The authors concluded that the developed method gives lower LOD for NSAIDs than other methods with similar UV detector or diode array detector (DAD), while using lower sample volumes and presenting shorter extraction time [35].

The monitoring of PAHs and aromatic amines using DLLME techniques assisted by ultrasounds (USA-DLLME) or air (AALLME) by applying DES in the pretreatment step was also proposed [22, 79]. Makos et al. [22] analysed 16 PAHs, whose description is shown in [22], in effluents from the production of bitumen using USA-DLLME 
coupled to GC-MS. The thymol:camphor (1:1) DES was used, leading to higher recoveries under optimized conditions and lower LODs (0.0039-0.0098 $\left.\mu \mathrm{g} \cdot \mathrm{L}^{-1}\right)$ [22]. In addition, Torbati et al. [79] reported the simultaneous derivatization and AALLME method based on the solidification of the DES composed of cholinium chloride and $n$-butyric acid coupled with GC-MS to determine aromatic amines (Figure 10.18) in tap, surface and river water, and wastewater. The DES was mixed with ethyl chloroformate, applied as a derivatization agent, and injected into an alkaline aqueous solution containing the target analytes at high temperature. The resulting mixture was drawn into a syringe, allowing the formation of a cloudy solution consisting of fine droplets of the extraction solvent, and which possess the derivatized aromatic amines. Then, the solution was subjected to low temperatures and the solidified extraction solvent (DES) was collected and analyzed [79]. The obtained results revealed LODs varying from 1.8 to $23 \mathrm{ng}^{-1} \mathrm{~L}^{-1}$, recoveries above $79 \%$ and enrichment factors in the interval between 790 and 940. It is important to highlight that the nontoxic nature of the DES individual components, as well as the simple procedures required to prepare DES in both works, bring major benefits compared to the hazardous solvents commonly used. Furthermore, this method requires a small amount of the extraction solvent, leading to the reduction of the risk to human health and environment $[22,79]$. 


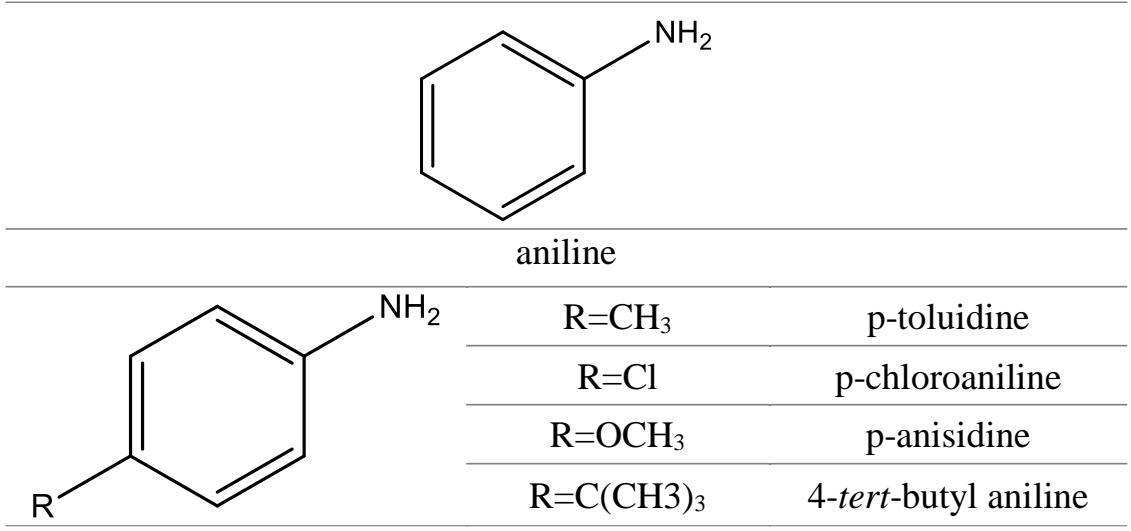

Fig. 10.18. Chemical structures of the studied aromatic amines.

In addition to liquid samples, some researchers applied DES to digest/solubilize solid samples aiming at monitoring trace-level contaminants, such as pesticides, PAHs (Figure 10.13 and 10.19) and heavy metals [17, 23, 27, 29]. 


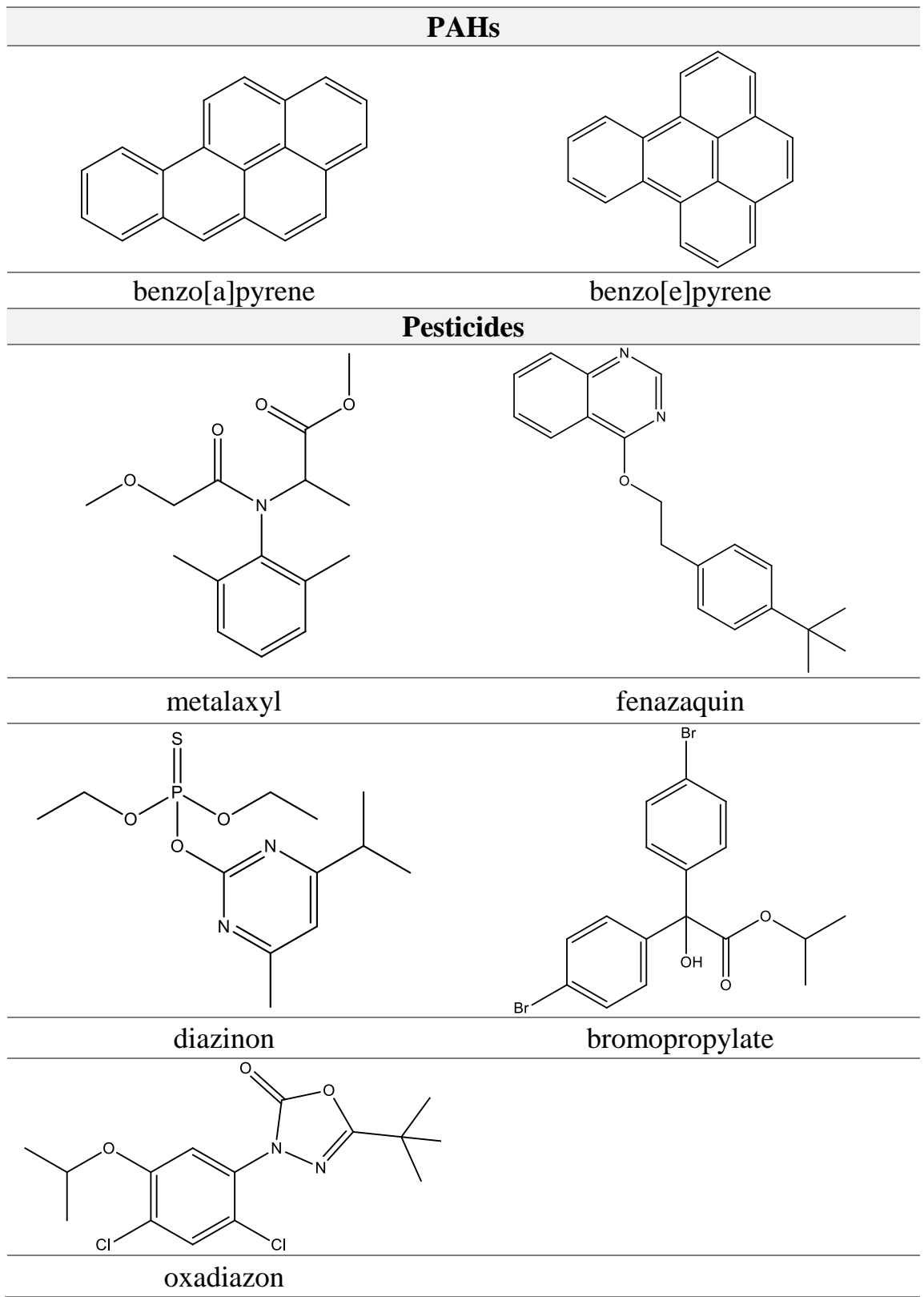

Fig. 10.19. Chemical structures of some of the studied PAHs and pesticides. 
Nezhad et al. [23] and Farajzadeh et al. [17] proposed the use of DES to improve the detection of pesticides and PAHs in fish and vegetable samples. Nezhad et al. [23] developed an innovative sample preparation method based on the complete dissolution of marine biological samples (fish and macroalgae) in the cholinium chloride:oxalic acid (1:2) DES and using minimized volumes of cyclohexane, allowing an efficient extraction of PAHs (anthracene, phenanthrene, fluoranthene, pyrene, benz[a]anthracene, chrysene, benzo[e] and benzo[a]pyrene, with the respective chemical structures depicted in Figure 10.13 and 10.19). The extracted PAHs were quantified by HPLC-FL with LODs ranging from 0.50 to $3.08 \mathrm{ng}^{\cdot} \mathrm{g}^{-1}$ [23]. The simplicity of the procedure, high extraction efficiency, short analysis time, and use of safe and inexpensive components are very attractive characteristics; however, the use of volatile organic solvents still needs to be avoided.

Farajzadeh et al. [17] presented a LPME approach for the extraction and preconcentration of some pesticides (Figure 10.19) (diazinon, metalaxyl, bromopropylate, oxadiazon, and fenazaquin), from different samples, including apple, grape and sour cherry juices and fresh beet, cucumber, potato and tomato. The solid samples were transformed into juice to be further analyzed, with no application of a digestion step mediated by DES. DES were applied in the extraction step only. The DES that displayed better results as extraction solvent is cholinium chloride: $p$-chlorophenol, in a molar ratio of 1:2. The dispersion of the extraction solvent into the aqueous phase was performed by changing the temperature, thereby leading to improvements in the extraction efficiency. Under the optimum extraction 
conditions, enrichment factors and extraction recoveries were obtained in the ranges of 280-465 and 56-93\%, respectively. Additionally, the LODs obtained ranged between $0.13-0.31 \mathrm{ng}^{\cdot} \mathrm{mL}^{-1}$ [17].

Habibollahi et al. [29] and Habibi et al. [27] quantified heavy metals in fish, soil and vegetables samples. The first group of authors [29] explored the application of DLLME and the subsequent solidification of DES (DLLME-SDES) prior to the metal ( $\mathrm{Hg}, \mathrm{Pb}, \mathrm{Cd})$ analysis by graphite furnace atomic absorption spectrometry (GF-AAS). In this technique, due to differences in the density between the aqueous phase and DES, the fine droplets of DES float at the top of the test tube, which are then transferred into an ice bath leading to the solidification of the DES, which is further melted before the GFAAS analysis. Since solid samples were investigated, these were subjected to a digestion step prior to the extraction step. The authors selected the 1octyl-3-methylimidazolium chloride (IL) and 1-undecanol to form a DES with a molar ratio of 1:2 as the extraction solvent. Under the optimum conditions, the enrichment factors of the target compounds are in the range of 114-172 and the LODs are in the range of 0.01$0.03 \mu \mathrm{g} \mathrm{kg}^{-1}$ [29]. The DLLME-SDES method does not require an organic solvent as disperser in comparison with other DLLME techniques, which is a major advantage to move to the requirements of green chemistry.

Habibi et al. [27] reported a novel and efficient digestion method of different tissues of fish samples (muscle, liver, and gills) based on the cholinium chloride:oxalic acid DES with a molar ratio of $1: 2$, with the goal of quantifying heavy metals $(\mathrm{Cu}, \mathrm{Zn}$, and $\mathrm{Fe})$ by flame atomic 
absorption spectrometry (FAAS) (Figure 10.20). The sample was dissolved in the DES and $\mathrm{HNO}_{3}$ was added. After a centrifugation step, the supernatant was filtered and analyzed by FAAS. Under optimized conditions, the extraction recovery of all elements was above $95.3 \%$. The proposed method was successfully applied in the determination of heavy metals in different tissues of fish samples. The authors pointed out the simplicity of the reported experimental method, and the high extraction efficiency, lower analysis time, and use of safe and inexpensive components, further suggesting the incorporation of this procedure in monitoring routines [27].

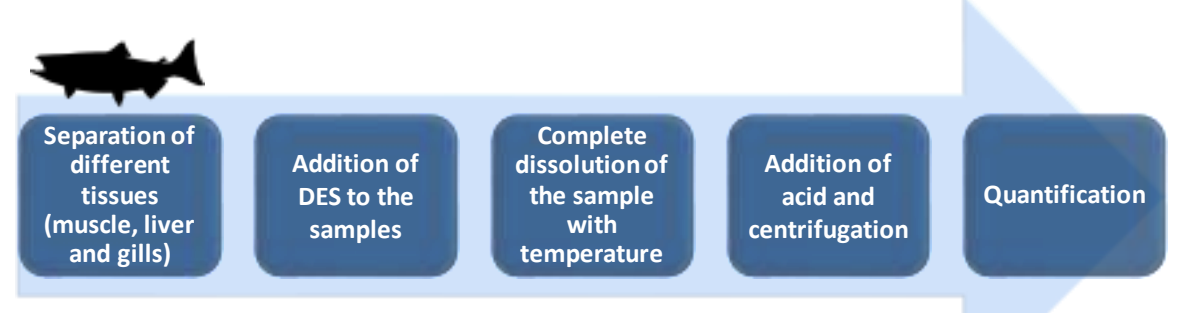

Fig. 10.20. Schematic representation of the digestion of solid samples using DES.

Overall, the interest in DES has grown significantly in the past few years since their first description [80]. However, these solvents display two major application areas: metal processing and as synthesis/dissolution media [59]. In this book chapter, it is described the use of DES as efficient solvents for the pretreatment of environmental samples while envisaging environmental monitoring of trace-level pollutants, opening a new path of applications for DES. Still a narrow 
range of DES has been used, emphasizing the need of expanding the types of hydrogen bond donors and acceptors that can be combined and hence increase the performance of these solvents in a wide variety of applications.

\section{Conclusions and future perspectives}

Albeit great advances have been achieved in the monitoring of environmental pollutants, the accurate identification and quantification of trace-level pollutants in complex matrices still require additional improvements. Based on this need, ILs and DES have been studied as alternative solvents in pretreatment techniques of environmental matrices in the field of environmental monitoring. These have been applied in the pretreatment of wastewater, industrial and municipal effluents, human fluids, wine, milk, honey, fish, macroalgae, vegetables and soil. A broad range of pollutants, such as PAHs, APIs, pesticides, heavy metals, and UV filters have been the target pollutants analyzed after pretreatment techniques involving ILs and DES. As reviewed in this work, these alternative solvents lead to improvements in environmental monitoring, allowing more accurate quantifications by promoting the target pollutants enrichment factor and recovery, and the LOD. The most relevant property of ILs and DES behind such successful results is their "designer solvent" ability, valuable to tailor the affinities and polarities of these extraction solvents according to the target compound. It should be remarked that ILs and DES can be also used in the digestion step of solid samples. 
Most ILs have been chosen based on their affinity for the target compounds, which may explain the focus on imidazolium-based cations combined with fluorinated anions. However, most of these ILs possess non-negligible toxicity and low biodegradability, reinforcing the need of looking for more sustainable ILs mainly derived from natural sources if the goal is to fulfill the Green Analytical Chemistry guidelines. Although with a different purpose, there are recent studies reporting the synthesis of new and non-toxic bio-based ILs that can also be used in extraction processes and in pretreatment techniques. Furthermore, the ILs recycling is an additional factor that should be considered in future studies in this field.

Although still in its infancy, DES have been investigated with the aim of environmental monitoring. In most of the reported works, cholinium chloride is the HBA species of choice, combined with HBDs such as oxalic acid, n-butyric acid, itaconic acid and p-chlorophenol. The recent research on DES reveals a growing interest of the scientific community in the creation of sustainable processes using more environmentally-friendly solvents. Still, the use of DES for the monitoring of pollutant compounds remains largely unexplored, leaving a vast opportunity to expand the knowledge in this field and to explore the dual role of DES, both as extraction solvents and digestion agents, ultimately resulting in the creation of integrated processes.

The development of sustainable processes is an undeniable current challenge. The research on ILs and DES as alternative solvents of the commonly applied hazardous organic solvents certainly contributes towards this goal. In this regard, these solvents should be properly 
designed to display high performance, and ideally should be prepared from natural sources or raw materials and should be of low cost, thus contributing to a decrease on both ecological and economic impacts.

Acknowledgements: This work was developed within the scope of the project CICECO-Aveiro Institute of Materials, FCT Ref. UID/CTM/50011/2019, financed by national funds through the FCT/MCTES. This work was financially supported by the project POCI-01-0145-FEDER-031106 (IonCytDevice) funded by FEDER, through COMPETE2020 - Programa Operacional Competitividade e Internacionalização (POCI), and by national funds (OE), through FCT/MCTES. Inês S. Cardoso acknowledges FCT for her PhD grant (SFRH/BD/139801/2018). M.G. Freire acknowledges the European Research Council under the European Union's Seventh Framework Programme (FP7/2007-2013) / ERC grant agreement nº 337753. 


\section{References}

1. Bolong N, Ismail AF, Salim MR, Matsuura T (2009) A review of the effects of emerging contaminants in wastewater and options for their removal. Desalination 239:229-246.

2. Gavrilescu M, Demnerová K, Aamand J, et al (2015) Emerging pollutants in the environment: Present and future challenges in biomonitoring, ecological risks and bioremediation. N Biotechnol 32:147-156.

3. Namiesnik J (2001) Modern Trends in Monitoring and Analysis of Environmental Pollutants. Polish J Environ Stud 10:127-140.

4. Jiang JQ, Zhou Z, Sharma VK (2013) Occurrence, transportation, monitoring and treatment of emerging micro-pollutants in waste water - A review from global views. Microchem J 110:292-300.

5. Schwarzenbach RP, Egli T, Hofstetter T, et al (2010) Global Water Pollution and Human Health. Annu Rev of Environment Resour. 35:109-136.

6. Mateo-Sagasta J, Marjani S, Turral H, Burke J (2017) Water pollution from agriculture: a global review. Int Water Manag Inst 35

7. Tchounwou PB, Yedjou CG, Patlolla AK, Sutton DJ (2012) Heavy Metal Toxicity and the Environment. Mol Clin Environ Toxicol 101:133-164.

8. Zenker A, Cicero MR, Prestinaci F, et al (2014) Bioaccumulation and biomagnification potential of pharmaceuticals with a focus to the aquatic environment. J Environ Manage 133:378-387.

9. Sousa JCG, Ribeiro AR, Barbosa MO, et al (2018) A review on environmental monitoring of water organic pollutants identified by EU guidelines. J Hazard Mater 344:146-162.

10. Advances in Chromatographic Analysis (2017), Edited by Ronaldo Frerreira do Nascimento. Avid Science

11. Fang G, Chen J, Wang J, et al (2010) N-Methylimidazolium ionic liquid-functionalized silica as a sorbent for selective solid-phase extraction of 12 sulfonylurea herbicides in environmental water and soil samples. J Chromatogr A 1217:1567-1574.

12. Gure A, Lara FJ, García-Campaña AM, et al (2015) Vortex-assisted ionic liquid dispersive liquid-liquid microextraction for the determination of sulfonylurea herbicides in wine samples by capillary high-performance liquid chromatography. Food Chem 170:348-353.

13. Zanella R, Primel EG, Machado SLO, et al (2002) Monitoring of the herbicide clomazone in environmental water samples by solid-phase extraction and high-performance liquid chromatography with ultraviolet detection. Chromatographia 55:573-577.

14. Shah J, Rasul Jan M, Ara B, Shehzad F-N (2011) Quantification of triazine herbicides in soil by microwave-assisted extraction and high-performance liquid chromatography. Environ Monit Assess 178:111-119.

15. Radović T, Grujić S, Petković A, et al (2015) Determination of pharmaceuticals and pesticides in river sediments and corresponding surface and ground water in the Danube River and tributaries in Serbia. Environ Monit Assess 187:4092.

16. Papadakis EN, Vryzas Z, Kotopoulou A, et al (2015) A pesticide monitoring survey in rivers and lakes of northern Greece and its human and ecotoxicological risk assessment. Ecotoxicol Environ Saf 116:1-9.

17. Farajzadeh MA, Shahedi Hojghan A, Afshar Mogaddam MR (2018) Development of a new temperature-controlled liquid phase microextraction using deep eutectic solvent for 
extraction and preconcentration of diazinon, metalaxyl, bromopropylate, oxadiazon, and fenazaquin pesticides from fruit juice and vegetable samples. J Food Compos Anal 66:90-97. liquid-liquid microextraction coupled to gas chromatography-mass spectrometry for the determination of organophosphorus pesticides. J Chromatogr A 1559:95-101.

19. Fan C, Liang Y, Dong H, et al (2017) In-situ ionic liquid dispersive liquid-liquid microextraction using a new anion-exchange reagent combined Fe3O4magnetic nanoparticles for determination of pyrethroid pesticides in water samples. Anal Chim Acta 975:20-29.

20. Florindo C, Branco LC, Marrucho IM (2017) Development of hydrophobic deep eutectic solvents for extraction of pesticides from aqueous environments. Fluid Phase Equilib 448:135-142 .

21. Wang H, Hu L, Li W, et al (2016) A rapid and simple pretreatment method for benzoylurea insecticides in honey samples using in-syringe dispersive liquid-liquid microextraction based on the direct solidification of ionic liquids. J Chromatogr A 1471:60-67.

22. Makoś P, Przyjazny A, Boczkaj G (2018) Hydrophobic deep eutectic solvents as "green" extraction media for polycyclic aromatic hydrocarbons in aqueous samples. J Chromatogr A. 1570:28-37.

23. Helalat-Nezhad Z, Ghanemi K, Fallah-Mehrjardi M (2015) Dissolution of biological samples in deep eutectic solvents: An approach for extraction of polycyclic aromatic hydrocarbons followed by liquid chromatography-fluorescence detection. J Chromatogr A 1394:46-53.

24. Pena MT, Casais MC, Mejuto MC, Cela R (2009) Development of an ionic liquid based dispersive liquid-liquid microextraction method for the analysis of polycyclic aromatic hydrocarbons in water samples. J Chromatogr A 1216:6356-6364.

25. Lau E V., Gan S, Ng HK (2010) Extraction Techniques for Polycyclic Aromatic Hydrocarbons in Soils. Int J Anal Chem 2010:1-9.

26. Abdolmohammad-Zadeh H, Sadeghi GH (2009) A novel microextraction technique based on 1-hexylpyridinium hexafluorophosphate ionic liquid for the preconcentration of zinc in water and milk samples. Anal Chim Acta 649:211-217.

27. Habibi E, Ghanemi K, Fallah-Mehrjardi M, Dadolahi-Sohrab A (2013) A novel digestion method based on a choline chloride-oxalic acid deep eutectic solvent for determining $\mathrm{Cu}, \mathrm{Fe}$, and $\mathrm{Zn}$ in fish samples. Anal Chim Acta 762:61-67.

28. Herce-Sesa B, López-López JA, Moreno C (2019) Selective ionic liquid solvent bar microextraction for estimation of ultra-trace silver fractions in marine waters. Sci Total Environ 650:27-33.

29. Habibollahi MH, Karimyan K, Arfaeinia H, et al (2018) Extraction and determination of heavy metals in soil and vegetables irrigated with treated municipal wastewater using new mode of dispersive liquid-liquid microextraction based on the solidified deep eutectic solvent followed by GFAAS. J Sci Food Agric 99:656-665.

30. Passos H, Sousa ACA, Pastorinho MR, et al (2012) Ionic-liquid-based aqueous biphasic systems for improved detection of bisphenol A in human fluids. Anal Methods 4:2664-2667.

31. Dinis TBV, Passos H, Lima DLD, et al (2015) One-step extraction and concentration of estrogens for an adequate monitoring of wastewater using ionic-liquid-based aqueous biphasic systems. Green Chem 17:2570-2579.

32. Paíga P, Lolić A, Hellebuyck F, et al (2015) Development of a SPE-UHPLC-MS/MS 
methodology for the determination of non-steroidal anti-inflammatory and analgesic pharmaceuticals in seawater. J Pharm Biomed Anal 106:61-70.

33. Kasprzyk-Hordern B, Dinsdale RM, Guwy AJ (2007) Multi-residue method for the determination of basic/neutral pharmaceuticals and illicit drugs in surface water by solidphase extraction and ultra performance liquid chromatography-positive electrospray ionisation tandem mass spectrometry. J Chromatogr A 1161:132-145.

34. Yao C, Li T, Twu P, et al (2011) Selective extraction of emerging contaminants from water samples by dispersive liquid-liquid microextraction using functionalized ionic liquids. $\mathbf{J}$ Chromatogr A 1218:1556-1566.

35. Wang R, Li W, Chen Z (2018) Solid phase microextraction with poly(deep eutectic solvent) monolithic column online coupled to HPLC for determination of non-steroidal antiinflammatory drugs. Anal Chim Acta 1018:111-118.

36. Abujaber F, Zougagh M, Jodeh S, et al (2017) Magnetic cellulose nanoparticles coated with ionic liquid as a new material for the simple and fast monitoring of emerging pollutants in waters by magnetic solid phase extraction. Microchem J 137:490-495.

37. Almeida HFD, Freire MG, Marrucho IM (2017) Improved monitoring of aqueous samples by the preconcentration of active pharmaceutical ingredients using ionic-liquid-based systems. Green Chem 19:4651-4659.

38. Net S, Delmont A, Sempéré R, et al (2015) Reliable quantification of phthalates in environmental matrices (air, water, sludge, sediment and soil): A review. Sci Total Environ 515-516:162-180.

39. Zhou Q, Zhang X, Xiao J (2009) Ultrasound-assisted ionic liquid dispersive liquid-phase micro-extraction: A novel approach for the sensitive determination of aromatic amines in water samples. J Chromatogr A 1216:4361-4365.

40. Shi F, Liu J, Liang K, Liu R (2016) Tris(pentafluoroethyl)trifluorophosphate-basd ionic liquids as advantageous solid-phase micro-extraction coatings for the extraction of organophosphate esters in environmental waters. J Chromatogr A 1447:9-16.

41. Chisvert A, Benedé JL, Salvador A (2018) Current trends on the determination of organic UV filters in environmental water samples based on microextraction techniques - A review. Anal Chim Acta 1034:22-38

42. Holbrey JD, Rogers RD (2002) Green Chemistry and Ionic Liquids : Synergies and Ironies Green Chemistry Approach - Process Management. Am Chem Soc 2-14.

43. Espino M, de los Ángeles Fernández M, Gomez FJV, Silva MF (2016) Natural designer solvents for greening analytical chemistry. TrAC - Trends Anal Chem 76:126-136 .

44. Zhao H, Xia S, Ma P (2005) Use of ionic liquids as "green" solvents for extractions. J Chem Technol Biotechnol 80:1089-1096.

45. Liu Y, Friesen JB, McAlpine JB, et al (2018) Natural Deep Eutectic Solvents: Properties, Applications, and Perspectives. J Nat Prod 81:679-690.

46. Passos H, Freire MG, Coutinho JAP (2014) Ionic liquids solutions as extractive solvents of value-added compounds from biomass. Green Chem 16:4786-4815.

47. Dupont J, De Souza RF, Suarez PAZ (2002) Ionic liquid (molten salt) phase organometallic catalysis. Chem Rev 102:3667-3692.

48. Freire MG, Cláudio AFM, Araújo JMM, et al (2012) Aqueous biphasic systems: a boost brought about by using ionic liquids. Chem Soc Rev 41:4966-4995.

49. Ranke J, Stolte S, Störmann R, et al (2007) Design of sustainable chemical products-the 
example of ionic liquids. Chem Rev 107:2183-2206.

50. Hallett JP, Welton T (2011) Room-temperature ionic liquids: Solvents for synthesis and catalysis. Chem Rev 111:3508-3576.

51. Plechkova N V., Seddon KR (2008) Applications of ionic liquids in the chemical industry. Chem Soc Rev 37:123-150.

52. Zhao H (2006) Innovative applications of ionic liquids as "green" engineering liquids. Chem Eng Commun 193:1660-1677.

53. Freire MG, Neves CMSS, Marrucho IM, et al (2010) Hydrolysis of tetrafluoroborate and hexafluorophosphate counter ions in imidazolium-based ionic liquids. J Phys Chem A 114:3744-3749.

54. Mondal D, Sharma M, Quental M V., et al (2016) Suitability of bio-based ionic liquids for the extraction and purification of $\operatorname{IgG}$ antibodies. Green Chem 18:6071-6081.

55. Hulsbosch J, De Vos DE, Binnemans K, Ameloot R (2016) Biobased Ionic Liquids: Solvents for a Green Processing Industry? ACS Sustain Chem Eng 4:2917-2931.

56. Paiva A, Craveiro R, Aroso I, et al (2014) Natural Deep Eutectic Solvents - Solvents for the 21st Century. ACS Sustain Chem Eng 2:1063-1071.

57. Abbott AP, Capper G, Davies DL, et al (2001) Preparation of novel, moisture-stable, Lewisacidic ionic liquids containing quaternary ammonium salts with functional side chains. Chem Commun 2010-2011.

58. Vanda H, Dai Y, Wilson EG, et al (2018) Green solvents from ionic liquids and deep eutectic solvents to natural deep eutectic solvents. Comptes Rendus Chim 21:628-638.

59. Smith EL, Abbott AP, Ryder KS (2014) Deep Eutectic Solvents (DESs) and Their Applications. Chem Rev 114:11060-11082.

60. Primel EG, Caldas SS, Marube LC, Escarrone ALV (2017) An overview of advances in dispersive liquid-liquid microextraction for the extraction of pesticides and emerging contaminants from environmental samples. Trends Environ Anal Chem 14:1-18.

61. Shamsipur M, Yazdanfar N, Ghambarian M (2016) Combination of solid-phase extraction with dispersive liquid-liquid microextraction followed by GC-MS for determination of pesticide residues from water, milk, honey and fruit juice. Food Chem 204:289-297.

62. Płotka-Wasylka J, Szczepańska N, de la Guardia M, Namieśnik J (2015) Miniaturized solidphase extraction techniques. TrAC - Trends Anal Chem 73:19-38.

63. Sun J, Liang Q, Han Q, et al (2015) One-step synthesis of magnetic graphene oxide nanocomposite and its application in magnetic solid phase extraction of heavy metal ions from biological samples. Talanta 132:557-563.

64. Yrieix C, Gonzalez C, Deroux JM, et al (1996) Countercurrent liquid/liquid extraction for analysis of organic water pollutants by GC/MS. Water Res 30:1791-1800.

65. López-Montilla JC, Pandey S, Shah DO, Crisalle OD (2005) Removal of non-ionic organic pollutants from water via liquid-liquid extraction. Water Res 39:1907-1913.

66. Andrade-Eiroa A, Canle M, Leroy-Cancellieri V, Cerdà V (2016) Solid-phase extraction of organic compounds: A critical review (Part I). TrAC - Trends Anal Chem 80:641-654.

67. Dinis TBV, Passos H, Lima DLD, et al (2018) Simultaneous extraction and concentration of water pollution tracers using ionic-liquid-based systems. J Chromatogr A 1559:69-77.

68. Hamed Mosavian MT, Es’Haghi Z, Razavi N, Banihashemi S (2012) Pre-concentration and determination of amitriptyline residues in waste water by ionic liquid based immersed droplet microextraction and HPLC. J Pharm Anal 2:361-365. 
69. Zhou QX, Gao YY (2014) Combination of ionic liquid dispersive liquid-phase microextraction and high performance liquid chromatography for the determination of triazine herbicides in water samples. Chinese Chem Lett 25:745-748.

70. Vichapong J, Burakham R, Santaladchaiyakit Y, Srijaranai S (2016) A preconcentration method for analysis of neonicotinoids in honey samples by ionic liquid-based cold-induced aggregation microextraction. Talanta 155:216-221.

71. Wang YL, You LQ, Mei YW, et al (2016) Benzyl Functionalized Ionic Liquid as New Extraction Solvent of Dispersive Liquid-liquid Microextraction for Enrichment of Organophosphorus Pesticides and Aromatic Compounds. Chinese J Anal Chem 44:942-949.

72. Benedé JL, Anderson JL, Chisvert A (2018) Trace determination of volatile polycyclic aromatic hydrocarbons in natural waters by magnetic ionic liquid-based stir bar dispersive liquid microextraction. Talanta 176:253-261.

73. Zhang Y, Lee HK (2012) Ionic liquid-based ultrasound-assisted dispersive liquid-liquid microextraction followed high-performance liquid chromatography for the determination of ultraviolet filters in environmental water samples. Anal Chim Acta 750:120-126.

74. Ge D, Lee HK (2012) Ionic liquid based hollow fiber supported liquid phase microextraction of ultraviolet filters. J Chromatogr A 1229:1-5.

75. Hashemi B, Zohrabi P, Kim KH, et al (2017) Recent advances in liquid-phase microextraction techniques for the analysis of environmental pollutants. TrAC - Trends Anal Chem 97:83-95.

76. Al-Saidi HM, Emara AAA (2011) The recent developments in dispersive liquid - liquid microextraction for preconcentration and determination of inorganic analytes. J Saudi Chem Soc 18:745-761.

77. Freire MG, Neves CMSS, Carvalho PJ, et al (2007) Mutual Solubilities of Water and Hydrophobic Ionic Liquids. J Phys Chem B 111:13082-13089.

78. Sharifan H, Klein D, Morse AN (2016) UV filters are an environmental threat in the Gulf of Mexico : a case study of Texas coastal zones. Oceanologia 58:327-335.

79. Torbati M, Mohebbi A, Farajzadeh MA, Afshar Mogaddam MR (2018) Simultaneous derivatization and air-assisted liquid-liquid microextraction based on solidification of lighter than water deep eutectic solvent followed by gas chromatography-mass spectrometry: An efficient and rapid method for trace analysis of aromatic amines in aqueous samples. Anal Chim Acta 1032:48-55.

80. Abbott AP, Boothby D, Capper G, et al (2004) Deep Eutectic Solvents Formed between Choline Chloride and Carboxylic Acids: Versatile Alternatives to Ionic Liquids. J Am Chem Soc 126:9142-9147. 